\title{
Femtosecond Laser Photoionization Time-of- Flight Mass Spectrometry of Nitro-aromatic Explosives and Explosives Related Compounds
}

\author{
Christopher Mullen,* Michael J. Coggiola, and Harald Oser \\ Molecular Physics Laboratory, SRI International, Menlo Park, California, USA
}

\begin{abstract}
The ultrafast laser-induced photoionization and photodissociation processes of the nitroaromatic containing explosive and explosive related compounds (ERCs) nitrobenzene (NB), 1,3-dinitrobenzene (DNB), m-nitrotoluene (MNT), 2,4-dinitrotoluene (DNT), and 2,4,6trinitrotoluene (TNT) have been investigated at three laser wavelengths and power densities using a time-of-flight mass spectrometer. Examination of the mass spectra of these compounds reveals the enhanced formation of the molecular ion $\left[\mathrm{M}^{+}\right]$when ultraviolet $(332 \mathrm{~nm})$ and visible $(495 \mathrm{~nm})$ light is used relative to infrared $(795 \mathrm{~nm}$ ) radiation. In addition, at $795 \mathrm{~nm}$ and a power density of $3.5 \times 10^{14} \mathrm{~W} / \mathrm{cm}^{2}$, the presence of a competition between multiphoton ionization (MPI) and Coulomb explosion (CE) channels is revealed by peak shape analysis, and is thought to be operative under these conditions for all of the molecules investigated. (J Am Soc Mass Spectrom 2009, 20, 419-429) (C 2009 Published by Elsevier Inc. on behalf of American Society for Mass Spectrometry
\end{abstract}

$\mathrm{T}$ The interaction of intense, ultrafast, laser pulses with atomic [1-4], small molecular systems [5-12], and polyatomic aromatic organic molecules [1323], has been the subject of intense investigation. These studies have focused on the fundamental interaction of the laser pulse with the atomic or molecular system, and have generally found a number of operative ionization and dissociation mechanisms present, which are sensitive to the laser wavelength and power density. In addition, a number of studies have also been dedicated to the investigation of the analytical usefulness of femtosecond laser ionization toward molecular specific detection. A prime example is the application to the ionization and detection of the explosives and explosives related compounds pioneered by Ledingham et al. [24-30]. Their studies focused on an understanding of the mass spectra obtained using ultrafast laser pulses in conjunction with time-of-flight mass spectrometry, $\mathrm{M}^{+}$ion formation, and specific molecular fragments that could be assigned to a particular precursor species. Of particular interest was the demonstration of isomer dependent mass spectra for the three isomers of nitrotoluene.

The motivation to apply femtosecond laser ionization to the study of explosives and ERCs originated from previous laser ionization work, which found that nanosecond laser ionization in the ultraviolet led to extensive molecular fragmentation [31-36]. The exten-

Address reprint requests to Dr. H. Oser, Molecular Physics Laboratory, SRI International, 333 Ravenswood Ave., Menlo Park, CA 94025, USA. E-mail: harald.oser@sri.com

* Current address: Thermo Fisher Scientific, 355 River Oaks Parkway, San Jose, CA 95134, USA. sive fragmentation was determined to be non-useful for species-specific identification, even though abundant $\mathrm{NO}^{+}$ions were observed in the mass spectra [37]. The presence of $\mathrm{NO}^{+}$in the mass spectra of these species naturally raised questions regarding its formation. Mechanistically, it was discovered that the dissociative lifetimes of the intermediate states involved in the ionization process were about a few hundred femtoseconds, and that this rapid dissociation led to the extensive fragmentation observed in the mass spectra. Further, the presence of $\mathrm{NO}^{+}$in the mass spectra of these species was attributed to rapid dissociation of the parent molecule $\left(\mathrm{RNO}_{2}\right)$ producing the $\mathrm{NO}_{2}$ fragment. The $\mathrm{NO}_{2}$ molecule undergoes an additional photon absorption from the ground state $\left(X^{2} \Pi\right)$ to the predissociative $\mathrm{B}^{2} \mathrm{~B}_{2}$ state, leading to $\mathrm{NO}\left(\mathrm{X}^{2} \Pi\right)$ and $\mathrm{O}\left({ }^{1} \mathrm{D}\right)$ atom fragments, followed by subsequent ionization by a $(1+1)$ REMPI process employing the $A^{2} \Sigma^{+}-X^{2} \Pi$ transition yielding $\mathrm{NO}^{+}$.

It was therefore desirable to devise a strategy for the ionization of these species that resulted in molecular ion formation, and/or molecular ion fragments that are strongly correlated to the precursor species. Two laserbased ionization techniques have shown promise in this regard; ultrafast laser ionization in conjunction with time-of-flight mass spectrometry as pioneered by Ledingham et al. [24] and more recently, laser singlephoton ionization time-of-flight mass spectrometry [38].

A necessary requirement for the advancement of ultrafast laser ionization mass spectrometry is an understanding of the ionization mechanism(s) operative under a given set of laser conditions. A generally accepted view of the ionization mechanism that can be
(C) 2009 Published by Elsevier Inc. on behalf of American Society for Mass Spectrometry. 1044-0305/09/\$32.00

doi:10.1016/j.jasms.2008.10.022
Published online November 6, 2008 Received November 7, 2007 Revised October 28, 2008 Accepted October 31, 2008 
anticipated when ultrafast laser pulses are employed has been developed by Levis and DeWitt [15]. They describe the interaction of the electric field of the laser pulse with the molecule, and find that when the power density is high enough, a transition from multiphoton ionization to field assisted or tunnel ionization occurs. The first reports of ultrafast laser ionization on explosives and ERCs found that the fast rate of up-pumping provided by the femtosecond laser pulse led to an enhancement in molecular ion formation for these species as well as a suppression of the dissociative states that lead to the highly fragmented mass spectra found when nanosecond pulses were employed. These studies, conducted at $800 \mathrm{~nm}$ [28], $412 \mathrm{~nm}$ [27], $375 \mathrm{~nm}$ [24-26], and $206 \mathrm{~nm}$ [29] found that the visible and UV wavelengths were generally better at producing the parent molecular ion. Further, the mass spectra taken at high power density in the $800 \mathrm{~nm}$ studies suggested the activity of Coulomb explosion (CE) channels. The latter inference was made from a combination of multiply charged atomic and molecular fragments present in a number of the mass spectra, a calculation of the adiabaticity parameter under the experimental conditions, and a consideration of the channels that could lead to the presence of multiply charged fragment species.

It is the goal of this work to further extend the understanding of the ionization mechanism(s) by investigating the mass spectra of the nitro containing aromatic species NB, DNB, MNT, DNT, and TNT at variable wavelengths and power densities.

\section{Experimental}

The ultrafast laser ionization of explosive and ERCs is studied using an instrument consisting of a reflectron time-of-flight mass spectrometer (Stefan Kaesdorf, Munich, Germany), a capillary inlet system, and a tunable femtosecond laser. In this configuration, the molecules are introduced into the mass spectrometer via a heated capillary inlet. The capillary inlet consists of $\sim 90 \mathrm{~cm}$ of $100 \mu \mathrm{m}$ i.d. deactivated fused silica capillary that can be heated to $250{ }^{\circ} \mathrm{C}$, which provides the necessary pressure drop to interface the sample to the ionization region of the mass spectrometer. $\mathrm{NO}_{2}(500 \mathrm{ppm}$ mixture in UHP He; Matheson Tri-Gas, Newark, CA), NB (Aldrich reagent grade, 99\%, Sigma-Aldrich, St Louis, MO), and MNT (Aldrich, $\geq 99 \%$ ) were delivered to the instrument at room-temperature. Solid samples of DNB (Aldrich, 97\%), DNT (Aldrich, 97\%), and TNT (recrystallized from a commercial source, approximate purity $\geq 98 \%$ ) were heated above their melting point and the headspace above the samples was transferred to the instrument by heating the capillary and probe to the same temperature.

Tunable laser frequencies are generated using an OPA (Spectra-Physics, OPA-800C, Mountain View, CA) pumped by a mode locked Ti:Sapphire oscillator-amplifier system (Spectra-Physics Tsunami and Spitfire) operating at $795 \mathrm{~nm}$ and $1 \mathrm{~mJ}$, at a $1 \mathrm{kHz}$ repetition rate.
The Spitfire laser polarization is horizontal and collinear with the time-of-flight mass spectrometer axis. The OPA generates tunable wavelengths between 480 to $530 \mathrm{~nm}$ by sum frequency mixing the signal beam $\left(\omega_{\text {signal }}\right)$ with the residual pump $\left(\omega_{\text {pump }}\right)$ beam in a nonlinear BBO crystal, where $\omega_{\text {out }}=\omega_{\text {pump }}+\omega_{\text {signal }}$, with $\omega_{\text {signal }}$ generated from the initial down conversion of the pump beam via $\omega_{\text {pump }}=\omega_{\text {idler }}+\omega_{\text {signal }}$. The final output pulse in this wavelength region is nominally 130 fs in duration, measured using a single shot autocorrelator (Positive Light), with an energy $\mathrm{E} \sim 30 \mu \mathrm{J}$. Wavelengths between 300 and $400 \mathrm{~nm}$ are produced by frequency quadrupling the signal beam $\left(4 \omega_{s}\right)$ with an output pulse energy $\mathrm{E} \sim 3 \mu \mathrm{J}$. Both the $480-530 \mathrm{~nm}$ and $300-400 \mathrm{~nm}$ beams are horizontally polarized. The laser beam was focused into the center of the ionization region of the mass spectrometer with a $150 \mathrm{~mm}$ planoconvex lens producing power densities calculated as 35 , 3.2 , and $0.73 \times 10^{13} \mathrm{~W} / \mathrm{cm}^{2}$, at $795 \mathrm{~nm}, 500 \mathrm{~nm}, 330 \mathrm{~nm}$, respectively.

The ions are created at ground potential between the repeller $\left(\mathrm{V}_{\text {rep }}=+680 \mathrm{~V}\right)$ and extraction $\left(\mathrm{V}_{\text {ext }}=-680 \mathrm{~V}\right)$ electrode (distance between electrodes $=20 \mathrm{~mm}$ ), and after acceleration are detected using a dual microchannel plate configuration, in conjunction with a $1 \mathrm{GHz}$ digitizer (Acqiris AP235, Agilent Technologies, Inc., Englewood, CO).

\section{Results and Discussion}

The mass spectra of NB, MNT, DNT, and TNT were taken at three wavelengths near $330 \mathrm{~nm}, 500 \mathrm{~nm}$, and $795 \mathrm{~nm}$ using a $150 \mathrm{~mm}$ focusing lens. The mass spectra of NB and TNT are presented in Figure 1 and Figure 2, respectively. The major peaks found for DNB, MNT, and DNT are presented in tabular format in the Supplementary Material section, which can be found in the electronic version of this article. The peaks summarized in the table, had to have at least a $5 \%$ or higher abundance compared to the peak with the highest

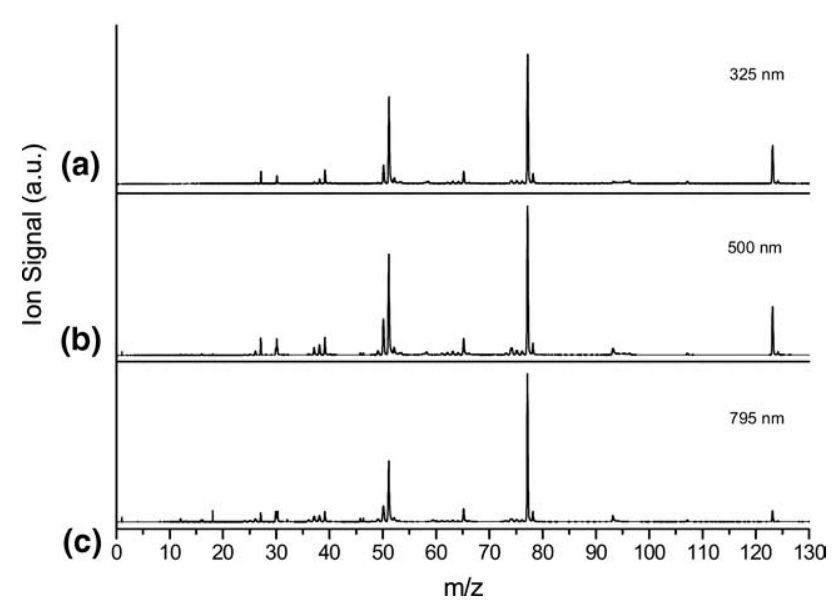

Figure 1. Nitrobenzene photoionization mass spectra taken at (a) $325 \mathrm{~nm}$, (b) $500 \mathrm{~nm}$, and (c) $795 \mathrm{~nm}$. 


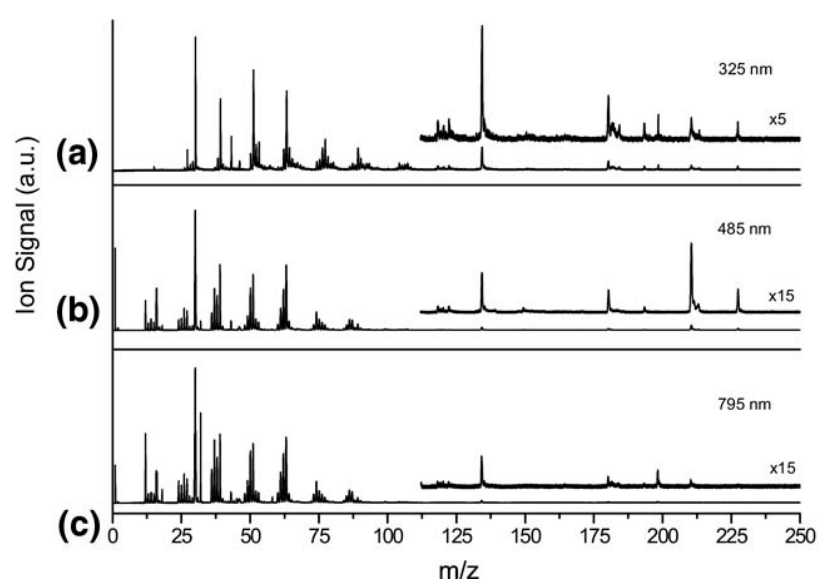

Figure 2. 2, 4, 6-trinitrotoluene mass spectra taken at (a) $325 \mathrm{~nm}$, (b) $485 \mathrm{~nm}$, and(c) and $795 \mathrm{~nm}$. Inserts of (a), (b), and (c) are expanded views of the mass region where the molecular ion (227 $\mathrm{m} / \mathrm{z}$ ) and high mass fragments appear.

amplitude. A discussion of the results for the individual molecules follows in the subsequent sections.

\section{Nitrobenzene}

The mass spectra of NB at wavelengths of $325 \mathrm{~nm}, 500$ $\mathrm{nm}$, and $795 \mathrm{~nm}$ are presented in Figure 1. Peaks at 51 $\mathrm{m} / \mathrm{z}$ and $77 \mathrm{~m} / \mathrm{z}$, corresponding to fragment species $\mathrm{C}_{4} \mathrm{H}_{3}^{4}$ and $\mathrm{C}_{6} \mathrm{H}_{5}^{+}$, respectively, dominate all three mass spectra. $\mathrm{M}^{+}$ion signal $[123 \mathrm{~m} / \mathrm{z}]$ is observed for all three wavelengths in varying amounts. The $325 \mathrm{~nm}$ and 500 nm spectra show nearly equal amounts of $\mathrm{M}^{+}$formation relative to fragment species, while $795 \mathrm{~nm}$ photoionization suppresses the $\mathrm{M}^{+}$ion signal, and somewhat accentuates low mass species as is evidenced by the appearance of $\mathrm{H}^{+}[1 \mathrm{~m} / \mathrm{z}]$ and $\mathrm{C}^{+}[12 \mathrm{~m} / \mathrm{z}]$ in the mass spectra. These results are generally in accord with previous findings at similar wavelengths and power densities. Kosmidis et al. [25] studied the photodissociation of NB induced by $375 \mathrm{~nm}, 90 \mathrm{fs}$ pulses, at power densities of $10^{13} \mathrm{~W} / \mathrm{cm}^{2}$, and found the ionization to be in accord with a three-photon process as is predicted from the ionization energy (IE) and wavelength em- ployed. They found the main ionic species to be $\mathrm{C}_{6} \mathrm{H}_{5}^{+}$ [77 m/z], $\mathrm{C}_{4} \mathrm{H}_{3}^{4}[51 \mathrm{~m} / \mathrm{z}], \mathrm{C}_{6} \mathrm{H}_{5} \mathrm{NO}_{2}^{+}[123 \mathrm{~m} / z], \mathrm{NO}^{+}$[30 $m / z], \mathrm{C}_{5} \mathrm{H}_{5}^{+}$[65], $\mathrm{C}_{3} \mathrm{H}_{3}^{4}[39 \mathrm{~m} / \mathrm{z}]$, and $\mathrm{C}_{6} \mathrm{H}_{5} \mathrm{O}^{+}$[93 m/z] in order of decreasing intensity. The mass spectrum in Figure 1a shows these ionic species with similar relative ratios.

The similarity of the mass spectra taken at $375 \mathrm{~nm}$ and $325 \mathrm{~nm}$ is a somewhat surprising result when the energetics of the ionization are more closely examined. The current recommendation for the IE of nitrobenzene is $9.94 \pm 0.08 \mathrm{eV}$ [39]. Three $325 \mathrm{~nm}$ photons equal 11.4 $\mathrm{eV}$, which for a three-photon ionization should activate the lower energy ionic dissociation channels listed in Table 1. In contrast, the $375 \mathrm{~nm}$ (three photons $=9.93$ $\mathrm{eV}$ ) experiments are predicted to impart roughly zero excess energy to the molecule, and inhibit the formation of the low-energy fragments. It therefore appears that the ionization is not consistent with a direct threephoton process. One possibility for this discrepancy could be accounted for by a more careful consideration of the appearance energies (AEs) of NB. Dissociation channels of $\mathrm{NB}$ are listed in Table 1 corresponding to the formation of $\mathrm{C}_{6} \mathrm{H}_{5} \mathrm{O}^{+}, \mathrm{NO}^{+}, \mathrm{C}_{6} \mathrm{H}_{5}^{+}, \mathrm{C}_{5} \mathrm{H}_{5}^{+}, \mathrm{C}_{3} \mathrm{H}_{3}^{4}$, and $\mathrm{C}_{4} \mathrm{H}_{3}^{4}$ at $10.9,10.9,11.08,11.08,12.63$, and $15.66 \mathrm{eV}$, respectively. All of these species are present in the mass spectra taken at $375 \mathrm{~nm}$ and $325 \mathrm{~nm}$. It seems that if MPI is to be assumed the dominant ionization mechanism (or AID: absorption-ionization-dissociation, using the nomenclature of Levis [15]), then the process is much more consistent with four- or five-photon ionization. In this fashion, the factor of $n=2.2$ from the power dependence of the ion signal from the study of Kosmidis et al. [25] could be interpreted as resulting from a two-photon transition to the intermediate state followed by a two- or three-photon transition to the ion state in a $(2+2)$ or $(2+3)$ MPI process. The gas-phase absorption spectrum of NB supports this assumption [40]. One photon at either wavelength (375 or 325$)$ is non-resonant, while the second photon promotes the molecule to the excited-state in a region with a high extinction coefficient. Subsequent one- and two-photon absorptions are then sufficient to ionize and also frag-

Table 1. Ionization potential and fragment ion appearance energies for nitrobenzene

\begin{tabular}{|c|c|c|c|c|}
\hline $\operatorname{IP}(e V)^{a}$ & Mass peak $(\mathrm{m} / \mathrm{z})$ & Appearance energy $(\mathrm{eV})$ & Reaction & Reference \\
\hline \multirow[t]{10}{*}{$9.94 \pm 0.08$} & 123 & & & \\
\hline & 30 & $11.04 \pm 0.05$ & $\mathrm{NO}^{+}+\mathrm{C}_{6} \mathrm{H}_{5}$ & b \\
\hline & & $10.89 \pm 0.04$ & & c \\
\hline & 51 & $11.40 \pm 0.05$ & $\mathrm{C}_{4} \mathrm{H}_{3}^{+}+\mathrm{NO}+\mathrm{C}_{2} \mathrm{H}_{2} \mathrm{O}$ & b \\
\hline & 65 & $11.30 \pm 0.05$ & $\mathrm{C}_{5} \mathrm{H}_{5}^{+}+\mathrm{CO}+\mathrm{NO}$ & $\mathrm{b}$ \\
\hline & & $11.08 \pm 0.16$ & & c \\
\hline & 77 & $11.14 \pm 0.05$ & $\mathrm{C}_{6} \mathrm{H}_{5}^{+}+\mathrm{NO}_{2}$ & $\mathrm{~b}$ \\
\hline & & $11.08 \pm 0.16$ & & c \\
\hline & 93 & $10.98 \pm 0.05$ & $\mathrm{C}_{6} \mathrm{H}_{5} \mathrm{O}^{+}+\mathrm{NO}$ & b \\
\hline & & $10.89 \pm 0.04$ & & c \\
\hline
\end{tabular}

aData taken from the evaluated ionization potentials, reference [39].

bPanczel, M.; Baer, T. Int. J. Mass Spectrom. Ion Processes 1984, 58, 43-61.

'Nishimura, T.; Das, P. R.; Meisels, G. G. J. Chem. Phys. 1986, 84, 6190-6199. 
ment the molecule according to the channels listed in Table 1. Interestingly, both wavelengths require five photons (16.55 and $19.05 \mathrm{eV})$ to reach the $\mathrm{C}_{4} \mathrm{H}_{3}^{4}$ threshold, the second most abundant ion in both mass spectra.

Ledingham et al. [24] have also studied the fs ionization/dissociation of NB at $375 \mathrm{~nm}$ using $50 \mathrm{fs}$ pulses and they indicate that the ion peaks observed in the mass spectrum of NB are evidence of a ladder switching mechanism where the dissociative channels below the ionization energy are somewhat "defeated" by the rapid up-pumping provided by the ultra-fast laser pulse. Again, the mass spectrum obtained at $325 \mathrm{~nm}$ in the present experiments agrees qualitatively with their results.

Tasker et al. [28] have also conducted a high mass resolution $(\mathrm{m} / \Delta \mathrm{m}=800)$ ultrafast laser ionization study on NB at $800 \mathrm{~nm}$ with $80 \mathrm{fs}$ pulses at power densities between $10^{14}$ to $10^{16} \mathrm{~W} / \mathrm{cm}^{2}$. For $\mathrm{NB}$, they observe the presence of $\mathrm{H}^{+}, \mathrm{C}^{+}, \mathrm{NO}^{+}, \mathrm{NO}_{2}^{+}, \mathrm{C}_{6} \mathrm{H}_{5}^{+}$, $\mathrm{C}_{6} \mathrm{H}_{5} \mathrm{O}^{+}, \mathrm{C}_{6} \mathrm{H}_{5} \mathrm{NO}^{+}$, and $\mathrm{C}_{6} \mathrm{H}_{5} \mathrm{NO}_{2}^{+}$, as well as doubly charged atomic and molecular fragments corresponding to $\mathrm{C}^{2+}, \mathrm{C}^{3+}, \mathrm{N}^{2+}, \mathrm{O}^{2+}, \mathrm{C}_{3} \mathrm{H}_{2}^{2+}, \mathrm{C}_{3} \mathrm{H}_{3}^{2+}, \mathrm{C}_{6} \mathrm{H}^{2+}$, $\mathrm{C}_{6} \mathrm{H}_{3}^{2+}$, and $\mathrm{C}_{6} \mathrm{H}_{5}^{2+}$ species. They argue that the $\mathrm{C}_{6} \mathrm{H}_{\mathrm{n}}^{2+}$ species are generated through the dissociation of the doubly charged transient molecular ion and the channels for their production should be similar to those observed for the singly charged species. Furthermore, they also assume that the presence of the $\mathrm{NO}_{2}^{+}$ion, previously unobserved in NB mass spectra, could be attributed to a charge separation process in the parent molecular ion, such as that from $\mathrm{C}_{6} \mathrm{H}_{5} \mathrm{NO}_{2}^{2+}$, although this transient species was not observed in their mass spectra. They support this argument with findings by Cooper et al. [41] who studied the fragmentation processes occurring in NB using synchrotron radiation photoionization time-of-flight mass spectrometry. Cooper et al. find the $\mathrm{AE}$ for $\mathrm{NO}_{2}^{+}$production to be $26 \pm 1$ $\mathrm{eV}$. Tasker et al. estimate the double ionization energy $\left(\mathrm{IE}^{2+}\right)$ of $\mathrm{NB}$, and find that it most likely lies in the range $26.7 \leq \mathrm{IE}^{2+} \geq 28.8 \mathrm{eV}$, i.e., within the experimental error of the synchrotron photoionization work. Energetically, this implies that the doubly ionized species could be the precursor to the observed $\mathrm{NO}_{2}^{+}$ion, which evolves through a charge separation process of the transient molecular intermediate.

We similarly do not directly observe the presence of $\mathrm{NB}^{2+}(m / z=61.5)$, but do find new indirect evidence for its presence, as revealed by peak shape analysis of $\mathrm{NO}_{2}^{+}$ (see section on Ionization Mechanism).

\section{1,3-Dinitrobenzene}

Fewer laser ionization studies on DNB have been conducted. Similar to the NB results, $330 \mathrm{~nm}$ and $500 \mathrm{~nm}$ are better at producing the molecular ion $\mathrm{C}_{6} \mathrm{H}_{4}\left(\mathrm{NO}_{2}\right)_{2}^{+}$ $(168 \mathrm{~m} / \mathrm{z})$, while $795 \mathrm{~nm}$ favors molecular ion suppression and the enhancement of low molecular weight atomic and molecular ion fragment species. The major difference in the 330 versus $500 \mathrm{~nm}$ mass spectra is the presence of the $112 \mathrm{~m} / \mathrm{z}$ peak in the $330 \mathrm{~nm}$ mass spectrum, which is most likely the $\mathrm{C}_{4} \mathrm{H}_{2} \mathrm{NO}_{3}^{4}$ ion. The NIST recommended value for the IE of DNB is $10.4 \mathrm{eV}$ and the only measurement of the AEs for DNB were conducted by Brown [42], who located the $\mathrm{C}_{6} \mathrm{H}_{4} \mathrm{NO}_{2}^{+}$ channel at $12.3 \pm 0.1 \mathrm{eV}$. This species is present in all three mass spectra.

\section{m-Nitrotoluene}

The nitro-substituted toluene series was also investigated as a function of wavelength. For all wavelengths employed, $330 \mathrm{~nm}, 500 \mathrm{~nm}$, and $795 \mathrm{~nm}$, the mass spectra show substantial $\mathbf{M}^{+}$ion formation [137 $\mathrm{m} / \mathrm{z}$ ]. MNT, with the nitro group at the $\mathrm{C} 3$ position shows only minimal $(\mathrm{M}-\mathrm{OH})^{+}[120 \mathrm{~m} / \mathrm{z}]$ and $(\mathrm{M}-\mathrm{O})^{+}[121$ $\mathrm{m} / \mathrm{z}$ ] loss, in contrast to the ortho isomer (not investigated) where the close proximity of the methyl and nitro groups leads to an elimination of the hydroxyl species. These results agree well with femtosecond measurements of Kosmidis et al. [25] at 375 and $750 \mathrm{~nm}$, and those of Ledingham et al. [24] at $375 \mathrm{~nm}$. The results of this study, and that of Tasker et al. [28], differ considerably in the relative amounts of $\mathbf{M}^{+}$[137 $\mathrm{m} / \mathrm{z}$ ], $\left(\mathrm{M}-\mathrm{NO}_{2}\right)^{+}[91 \mathrm{~m} / \mathrm{z}]$, and $\mathrm{C}^{+}[12 \mathrm{~m} / \mathrm{z}]$ signal produced, with the current experiments favoring the formation of the former two species. The difference in the mass spectra is most likely attributed to the difference in the power density of the experiments. Tasker et al. [28] conducted their experiments at $3.8 \times 10^{15}$ and $1.2 \times 10^{16}$ $\mathrm{W} / \mathrm{cm}^{2}$, while the current experiments were conducted at a calculated power density of $3.5 \times 10^{14} \mathrm{~W} / \mathrm{cm}^{2}$. The higher power density is thought to be responsible for the suppression of these two high-mass signals. This is also reflected in the degree of multiply charged atomic fragments produced in their mass spectra, including $\mathrm{C}^{4+}$ and $\mathrm{C}^{3+}$, which are not present to an appreciable extent in our mass spectra taken at the lower power density.

\section{2,4-Dinitrotoulene}

In contrast to the monosubstituted MNT species, $\mathrm{M}^{+}$ ion formation [182 $\mathrm{m} / \mathrm{z}$ ] is not the favored process, and fragmentation products dominate the mass spectra. However, all three wavelengths produce some $\mathrm{M}^{+}$ signal. Likewise, most of the high mass molecular fragments contribute only a small portion to the total ion signal.

Qualitative differences in the mass spectra of DNT obtained with $332 \mathrm{~nm}$ pulses in comparison to the $170 \mathrm{fs}$ duration, $206 \mathrm{~nm}$ pulses of Weickhardt and Tonnies [29], and Tonnies et al. [43] are the observation of DNT $\mathrm{M}^{+}$ion signal, although the magnitude of the signal is quite small. Two plausible explanations for the appearance of the $\mathrm{M}^{+}$ion at $332 \mathrm{~nm}$ are the better signal to noise ratio of the $332 \mathrm{~nm}$ experiments, or alternatively, a wavelength-dependent ionization process. Ledingham et al. [24] used $50 \mathrm{fs}$ irradiation at $375 \mathrm{~nm}$ to study 
DNT and obtained mass spectra, and found that the highest molecular weight species in the mass spectrum was $(\mathrm{M}-\mathrm{OH})^{+}[165 \mathrm{~m} / z]$, with high yields of $\mathrm{H}^{+}, \mathrm{NO}^{+}$, $\mathrm{C}_{5} \mathrm{H}_{\mathrm{n}}^{+}, \mathrm{C}_{6} \mathrm{H}_{\mathrm{n}}^{+}$, and $\mathrm{C}_{7} \mathrm{H}_{\mathrm{n}}^{+}$present. Since the two experiments are conducted at unique wavelength and power densities, it is rather difficult to draw conclusions regarding the presence of the parent molecular ion, although it is quite likely that the outcome of the ionization and dissociation of these photo-labile molecules is sensitive to the product of the wavelength and power density used.

\section{2,4,6-Trinitrotoluene}

The mass spectra of the final molecule in the series, TNT, are shown in Figure 2. Observations similar to those made for DNT are applicable to TNT, with the exception that TNT shows a lower propensity for molecular ion formation, $\mathrm{M}^{+}$[227 $\left.\mathrm{m} / \mathrm{z}\right]$, which has been previously noted [29, 43]. The high mass fragments consist mainly of the $\mathrm{OH}, \mathrm{NO}$, and $\mathrm{NO}_{2}$ loss products: $(\mathrm{M}-\mathrm{OH})^{+}[210 \mathrm{~m} / \mathrm{z}],(\mathrm{M}-2(\mathrm{OH}))^{+}[193 \mathrm{~m} / \mathrm{z}],(\mathrm{M}-$ $\mathrm{OH}-\mathrm{NO})^{+}[180 \mathrm{~m} / \mathrm{z}]$, and $\left(\mathrm{M}-\mathrm{OH}-\mathrm{NO}-\mathrm{NO}_{2}\right)^{+}[134$ $\mathrm{m} / \mathrm{z}$ ]. Differences in the mass spectra again occur at 325 $\mathrm{nm}$ excitation, as this set of experimental conditions produces a small amount of the molecular ion, in contrast to the $206 \mathrm{~nm}$ experiments of Weickhardt and Tonnies [29] and Tonnies et al. [43] The same holds true in comparison to the $375 \mathrm{~nm}, 50 \mathrm{fs}$ duration work of Ledingham et al. [24] where the $\mathrm{M}^{+}$ion of TNT is absent.

Examination of the TNT mass spectra in Figure 2 again reveals that the UV and visible wavelengths are better at molecular ion formation than is $795 \mathrm{~nm}$ irradiation, even though the degree of fragmentation and the fragment ion species are similar. An examination of the peak shape in the mass spectra at $\sim 330 \mathrm{~nm}, \sim 500$ $\mathrm{nm}$, and $795 \mathrm{~nm}$ reveals differences in the ionization mechanism as the wavelength and power density change in these experiments.

\section{Ionization Mechanism}

As previously mentioned, a number of studies have been dedicated to the fundamental interaction of intense laser fields with molecular systems. Levis and DeWitt [15] have proposed a field mediated coupling mechanism between near-IR radiation and the molecule resulting in excitation that causes both electron ejection and subsequent dissociation. They developed a qualitative model of the ionization regime that is anticipated under specific laser conditions and is defined by the adiabaticity parameter, $\gamma$

$$
\gamma=\sqrt{\frac{2 I E m_{e} \omega_{0}^{2}}{e^{2} E_{0}^{2}}}
$$

where IE is the ionization energy of the molecule, $\omega_{0}$ is the laser frequency, $\mathrm{m}_{\mathrm{e}}$ is the mass of an electron, $\mathrm{e}$ is the electron charge, and $\mathrm{E}_{0}$ is the amplitude of the laser electric field, which is related to the intensity of the radiation, $\mathrm{I}$, via

$$
E_{0}=\left(\frac{2 I}{\varepsilon_{0} c}\right)^{1 / 2}
$$

where $\varepsilon_{0}$ is the vacuum permittivity, and $\mathrm{c}$ is the speed of light. If $\gamma \gg 1$, MPI can be anticipated, and if $\gamma \ll 1$, the tunnel or field ionization regime can be expected. Tunnel/field ionization is oftentimes easily recognizable in time-of-flight mass spectra as ion species resulting from the electron ejection and subsequent rapid dissociation, i.e., Coulomb explosion, attain broadened peak shapes due to the kinetic energy imparted to these species upon separation. The Coulomb explosion process is best represented as follows

$$
M^{n+} \rightarrow F_{1}^{n_{1}^{+}}+F_{2}^{n_{2}^{+}}+\ldots F_{k}^{n_{k}^{+}}+N_{1}+N_{2}+\ldots N_{j}
$$

where the $F_{k} s$ are fragment ions and the $N_{j} s$ represent neutral species. When the power density is sufficiently high, further decomposition and ionization of the ionic and neutral products is also possible and results in the production of mainly atomic fragments according to

$$
F_{k}^{n+} \rightarrow A^{n_{1}^{+}}+B^{n_{2}^{+}}+\ldots C^{n_{1}^{+}}
$$

where $A, B$, and $C$ represent the atomic species.

Using NB as an example, the calculated values of the adiabaticity parameter are: $\gamma=0.29$ at $795 \mathrm{~nm}$ and a power density of $3 \times 10^{14} \mathrm{~W} / \mathrm{cm}^{2} ; \gamma=1.4$ at $500 \mathrm{~nm}$ and $3.2 \times 10^{13} \mathrm{~W} / \mathrm{cm}^{2} ; \gamma=4.5$ at $330 \mathrm{~nm}$ and $7.3 \times 10^{12}$ $\mathrm{W} / \mathrm{cm}^{2}$. Since the adiabaticity parameter is dependent on the square root of the ionization energy, and the ionization energies for the ERCs investigated are all within the range of $1 \mathrm{eV}$ of $\mathrm{NB}$, the adiabaticity parameter shows a similar nominal value for all the compounds explored. It is therefore anticipated that a shift in the ionization mechanism from tunnel ionization to MPI will occur as the wavelength and power density is decreased in these experiments. Figure 3 presents an expanded view of the low mass region near $30 \mathrm{~m} / \mathrm{z}$ and $46 \mathrm{~m} / z$ for NB, DNB, MNT, DNT, and TNT, respectively, as well as a mass spectrum from a 500 ppm mixture of $\mathrm{NO}_{2}$ in UHP He (Figure 3f). As can be seen in Figure 3, the peak shapes for $\mathrm{NO}^{+}$and $\mathrm{NO}_{2}^{+}$from the nitroaromatic compounds in all cases consist of a forward and backward component consistent with a charge separation and Coulomb explosion process with resultant kinetic energy release. It is also evident from Figure 3 that this process is specific to the nitro-aromatic species, because the $\mathrm{NO}^{+}$and $\mathrm{NO}_{2}^{+}$ion peak shapes from the 500 ppm $\mathrm{NO}_{2}$ mixture shows normal singlet structure. The insets for Figure $3 a-d$ show the spectral peak shapes when the signal is multiplied by the indicated scaling factors (open circles with dash). It is worthwhile noting that the degree of nitro substitution 


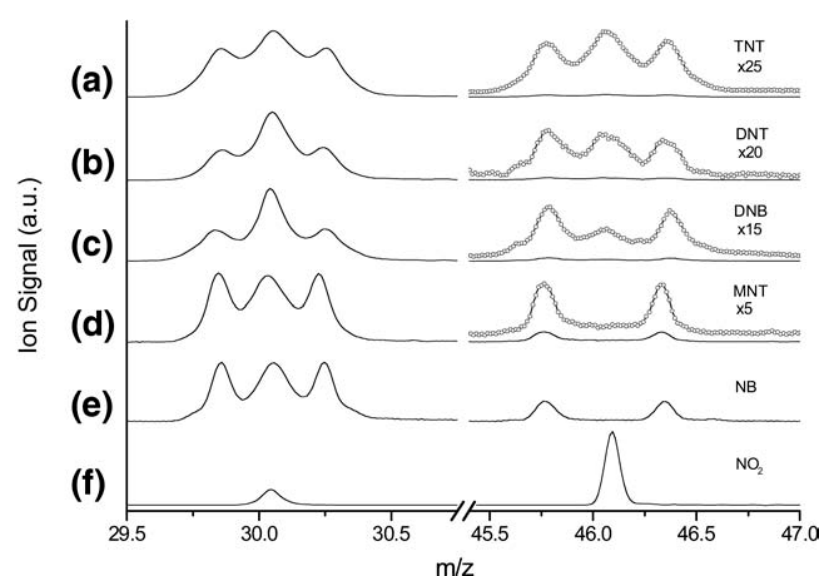

Figure 3. Expanded view mass spectra of the $\mathrm{NO}^{+}$and $\mathrm{NO}_{2}^{+}$ region of the mass spectrum for (a) TNT, (b) DNT, (c) DNB, (d) $\mathrm{MNT},(\mathbf{e}) \mathrm{NB},(\mathbf{f}) \mathrm{NO}_{2}$. In (a) through (d), the mass spectra have been multiplied by the indicated factor to aid in visualization of the peak shape for the $\mathrm{NO}_{2}^{+}$species (open circles).

influences the ionization process. Mono-substituted species (NB and MNT) show only the Coulomb explosion component in $\mathrm{NO}_{2}^{+}[46 \mathrm{~m} / \mathrm{z}]$, while the di-substituted species (DNB and DNT) show components from an explosion event, as well as a direct component (the middle ion peak) originating from an MPI process. Similarly, the tri-substituted species, TNT, demonstrates a peak shape indicative of both processes for $\mathrm{NO}_{2}^{+}$. For $\mathrm{NO}^{+}[30 \mathrm{~m} / \mathrm{z}]$ the situation is similar, except that both channels are active in all of the nitro-substituted species, with the relative activity dependent on the degree of substitution. In regard to the $\mathrm{NO}^{+}$structure from the nitro-aromatics, the portion attributed to the CE process is not likely to arise from dissociation of the parent nitro-aromatic into $\mathrm{NO}_{2}$ and products, followed by subsequent ionization and CE. Under these circumstances the peak shape would more closely mirror that of $\mathrm{NO}_{2}$ in Figure 3f. Further, one would anticipate a ratio of $\mathrm{NO}^{+} / \mathrm{NO}_{2}^{+}$similar to that of Figure $3 \mathrm{f}$, which is not observed in any of the mass spectra.

The difference in arrival times for the ions initially ejected towards and away from the detector can be used to obtain the kinetic energy release (KER) from the $\mathrm{CE}$ process. The equation is given by [44]

$$
E_{K E R}+\frac{\left(U_{1}-U_{2}\right)^{2}}{8 m d^{2}} q^{2} \Delta t^{2}
$$

where $U_{1}$ is the potential of the repeller plate, $U_{2}$ is the potential of the extraction plate, $\mathrm{d}$ is the distance between the plates, $\mathrm{m}$ is the mass of the ion, $\mathrm{q}$ is the charge of the ion, and $\Delta \mathrm{t}$ is the difference in flight time between the forward and backward components of the ion peak. The calculated KERs for the nitroaromatics are shown in Table 2. The KER for the $\mathrm{NO}^{+}$ and $\mathrm{NO}_{2}^{+}$fragments are well described by $2.2 \pm 0.3 \mathrm{eV}$ and $2.0 \pm 0.2 \mathrm{eV}$, respectively, for the species investigated. The time-of-flight synchrotron photoionization study of NB by Cooper et al. [41] examined the KER of the $\mathrm{NO}_{2}^{+}$fragment as a function of photon energy between 11 and $31 \mathrm{eV}$. They found the peak width of the $\mathrm{NO}_{2}^{+}$fragment to remain constant as a function of photon energy, within experimental uncertainty, at photon energies of 28.5, 29.8, and $31 \mathrm{eV}$, and found the KER to be consistent with a maximum translational energy of $2.8 \mathrm{eV}$. They attribute this result to the presence of the $\mathrm{NB}^{2+}$ transient ion undergoing a $\mathrm{CE}$ process to form two singly charged positive species and possibly one or more neutral fragments. It seems that although the media through which ionization is achieved is quite different in both experiments, ultrafast laser pulses at high power density, versus single photon ionization between 11-31 eV, both process access the transient $\mathrm{NB}^{2+}$ ion, and result in similar translational energy releases upon $\mathrm{CE}$. This further indicates that the $\mathrm{NB}^{2+}$ ion is undergoing charge separation from a similar critical distance in both experiments. At $31 \mathrm{eV}$, Cooper et al. [41] also find a central component to the $\mathrm{NO}_{2}^{+}$peak shape (absent in these experiments for $\mathrm{NB}$, and MNT, but present for DNB, DNT, and TNT), which they attribute to singly charged ion decomposition. These results suggest that the product channels in NB ionization using fs laser pulses are at least somewhat similar to those identified in the synchrotron experiments. The similarity of the KER observed for $\mathrm{NO}^{+}$and $\mathrm{NO}_{2}^{+}$from NB, MNT, DNB, DNT, and TNT suggest that all of these molecules support transient doubly, and possibly higher, charged species.

There is additional evidence in the mass spectra to support this claim. Figure 4 shows the expanded views of the mass spectrum of NB taken at $795 \mathrm{~nm}$ (Figure 1c), at a power density of $3.5 \times 10^{14} \mathrm{~W} / \mathrm{cm}^{2}$. The low intensity split ion peak in Figure 4 a centered at $\mathrm{m} / \mathrm{z}=$ 37.5 , corresponding to $\left(\mathrm{M}-\mathrm{NO}_{2}-2 \mathrm{H}\right)^{2+}\left[\mathrm{C}_{6} \mathrm{H}_{3}^{2+}\right]$ also shows a two component forward and backward structure indicating that it comes from a CE process, for which a number of channels could exist. A singlet structure of this peak would indicate that the $\mathrm{C}_{6} \mathrm{H}_{3}^{2+}$ species came from the dissociation of a multiply charged molecule into one ionic and one or more neutral fragments. Tasker et al. [28] have previously identified this ion peak in their study of NB using 800 $\mathrm{nm}, 80 \mathrm{fs}$ pulses at $1.1 \times 10^{15} \mathrm{~W} / \mathrm{cm}^{2}$ and $3.0 \times 10^{15}$ $\mathrm{W} / \mathrm{cm}^{2}$ and attributed its presence to the dissociation of the transient doubly charged molecular ion, i.e., $\mathrm{NB}^{2+} \rightarrow \mathrm{C}_{6} \mathrm{H}_{\mathrm{n}}^{2+}+\mathrm{NO}_{2}$. The doublet structure observed in our experiment is inconsistent with this assignment,

Table 2. Calculated kinetic energy release $(\mathrm{eV})$

\begin{tabular}{lcc}
\multicolumn{1}{c}{ Molecule } & $\mathrm{NO}$ & $\mathrm{NO}_{2}$ \\
& $(30 \mathrm{~m} / \mathrm{z})$ & $(46 \mathrm{~m} / \mathrm{z})$ \\
\hline \hline Nitrobenzene [NB] & $2.3 \pm 0.3$ & $2.1 \pm 0.2$ \\
m-Nitrotoluene [MNT] & $2.3 \pm 0.3$ & $2.1 \pm 0.2$ \\
1,3-Dinitrobenzene [DNB] & $2.2 \pm 0.3$ & $1.9 \pm 0.2$ \\
2,4-Dinitrotoluene [DNT] & $2.3 \pm 0.3$ & $1.9 \pm 0.2$ \\
2,4,6-Trinitrotoluene [TNT] & $2.4 \pm 0.3$ & $2.1 \pm 0.2$ \\
\hline
\end{tabular}



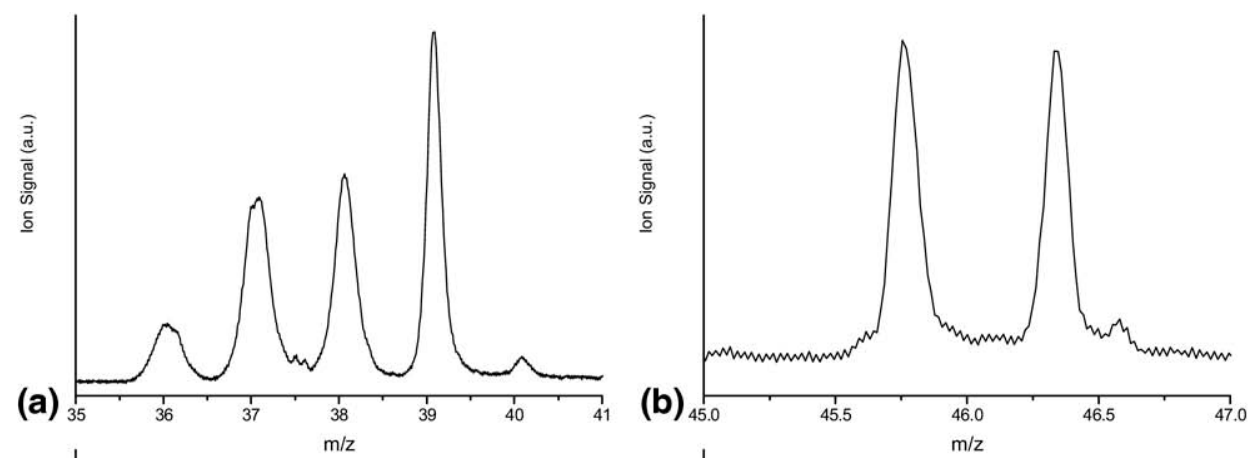

(c)
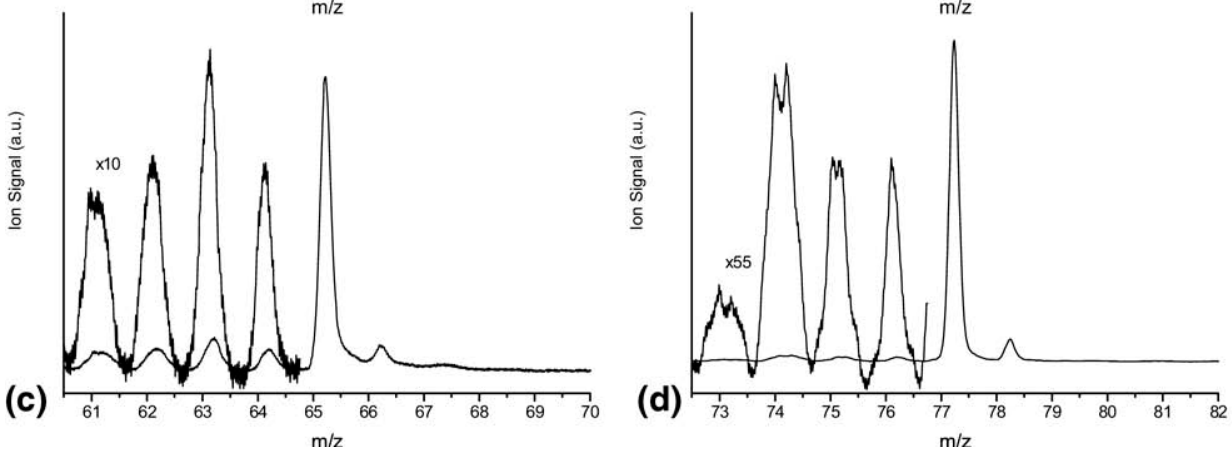

Figure 4. Expanded views of the mass spectrum of NB taken at $795 \mathrm{~nm}$ and a power density of $3.5 \times$ $10^{14} \mathrm{~W} / \mathrm{cm}^{2}$ in mass regions where split structure has been observed. The spectra in (c) and (d) have been multiplied by the indicated factors for clarity, and also to give an indication of their relative contribution to the mass spectra.

and it is unclear whether the difference in power density between the two experiments, $\sim 10^{15} \mathrm{~W} / \mathrm{cm}^{2}$ in the Tasker et al. study versus $\sim 10^{14} \mathrm{~W} / \mathrm{cm}^{2}$ in the current study could account for the difference. One would anticipate the higher power density studies to also involve similar ion processes. It is most likely the difference in the mass spectrometer extraction and acceleration conditions that leads to the difference in peak shape in the mass spectra from the two studies.

In contrast, the low intensity ion peak at $\mathrm{m} / \mathrm{z}=46.5$, corresponding to $(\mathrm{M}-\mathrm{NO})^{2+}\left[\mathrm{C}_{6} \mathrm{H}_{5} \mathrm{O}^{2+}\right]$ in Figure $4 \mathrm{~b}$ shows a singlet structure, the forward trajectory (shorter flight time) component does not appear to be superimposed on the $\mathrm{NO}_{2}^{+}$ion peak. Following the same argument, the singlet peak shape implies that this species originated from a dissociation event, resulting in ion and neutral fragments. The only possibility for this channel is $\mathrm{C}_{6} \mathrm{H}_{5} \mathrm{O}^{2+}+\mathrm{NO}$. Cooper et al. [41] find a two component peak shape for $\mathrm{NO}^{+}$at energies above $25 \mathrm{eV}$, and attribute the broad, high kinetic energy component of the peak to the decomposition of a doubly charged ion into two singly charged species, one of which is $\mathrm{NO}^{+}$.

A question naturally arises regarding the presence of the split peak structure for $\mathrm{NO}^{+}$and $\mathrm{NO}_{2}^{+}$. If these species are truly the fragment ions (the $F_{k}^{n_{k}^{+}}$species of eq 3) resulting from the $\mathrm{CE}$ of a transient multiply charged ion, then a number of other fragment ions should be present in the mass spectra with similar peak structures. In fact, Figure $4 \mathrm{c}$ and d do contain fragment species (at low intensities) with split structure indicative of a CE process. The $\mathrm{C}_{5} \mathrm{H}_{\mathrm{n}}^{+}$series at 60 through $65 \mathrm{~m} / \mathrm{z}$ (splitting most obvious for $m / z=61$, broadening for $m / z=62-65$ ) suggests the presence of channels resulting in the explosion of NB to fragment species

$$
\begin{aligned}
& \mathrm{C}_{5} \mathrm{H}_{\mathrm{m}}^{+}+\mathrm{NO}_{2}^{+}+\mathrm{CH}_{n-\mathrm{m}} \\
& \mathrm{C}_{5} \mathrm{H}_{\mathrm{m}}^{+}+\mathrm{O}^{+}+\mathrm{NO}+\mathrm{CH}_{n-\mathrm{m}} \\
& \mathrm{C}_{5} \mathrm{H}_{\mathrm{n}}^{+}+\mathrm{NO}^{+}+\mathrm{CO} \\
& \mathrm{C}_{4} \mathrm{H}_{\mathrm{m}} \mathrm{O}^{+}+\mathrm{NO}^{+}+\mathrm{C}_{2} \mathrm{H}_{n-\mathrm{m}}
\end{aligned}
$$

when only CEs into two charged species are considered, and the neutral species are included for mass balance and may not necessarily represent the actual neutral product(s).

Similarly, the $\mathrm{C}_{6} \mathrm{H}_{\mathrm{n}}^{+}$series at 72 through $77 \mathrm{~m} / \mathrm{z}$ suggest the presence of channels resulting in the explosion to

$$
\begin{aligned}
& \mathrm{C}_{6} \mathrm{H}_{\mathrm{m}}^{+}+\mathrm{NO}_{2}^{+}+\mathrm{H}_{n-\mathrm{m}} \\
& \mathrm{C}_{6} \mathrm{H}_{\mathrm{m}}^{+}+\mathrm{O}^{+}+\mathrm{NO}+\mathrm{H}_{n-\mathrm{m}} \\
& \mathrm{C}_{5} \mathrm{H}_{\mathrm{m}} \mathrm{O}^{+}+\mathrm{NO}^{+}+\mathrm{CH}_{n-\mathrm{m}}
\end{aligned}
$$

To further illustrate this hypothesis, Table $3 a$ and $b$ list potential product channels for NB Coulomb explosion that result in the creation of the $\mathrm{C}_{5} \mathrm{H}_{\mathrm{n}}^{+}$and $\mathrm{C}_{6} \mathrm{H}_{\mathrm{n}}^{+}$ species that involve $\mathrm{NO}_{2}^{+}$and $\mathrm{NO}^{+}$, respectively. With the series 60 to $65 \mathrm{~m} / \mathrm{z}$ in mind, the $\mathrm{CE}$ channels resulting in the formation of $\mathrm{NO}_{2}^{+}$seem much more plausible than those forming $\mathrm{NO}^{+}$, because the $\mathrm{NO}^{+} \mathrm{CE}$ series forms $\mathrm{C}_{4} \mathrm{H}_{\mathrm{n}} \mathrm{O}^{+}$species at masses 64 through $69 \mathrm{~m} / \mathrm{z}$, the latter three of which are absent in the mass spectrum (Figure 4c). The same holds true for the $\mathrm{C}_{6} \mathrm{H}_{\mathrm{n}}^{+}$series at 72 through $77 \mathrm{~m} / \mathrm{z}$. The $\mathrm{CE}$ series resulting in the formation of $\mathrm{NO}_{2}^{+}$favors the formation of 72 through $77 \mathrm{~m} / \mathrm{z}$, while the channels resulting in the formation of $\mathrm{NO}^{+}$result in the 
Table 3(a). Potential CE pathways involved in the formation of $\mathrm{NO}_{2}^{+}$

\begin{tabular}{|c|c|c|c|c|c|c|c|}
\hline Reactant & & $\operatorname{lon}_{1}^{+}$ & & $\operatorname{lon}_{2}^{+}$ & & Neutral & {$\left[\mathrm{m}_{1}, \mathrm{~m}_{2}, \mathrm{~N}\right]$} \\
\hline \multirow[t]{29}{*}{$\mathrm{C}_{6} \mathrm{H}_{5} \mathrm{NO}_{2}$} & $\rightarrow$ & $\mathrm{C}_{6} \mathrm{H}_{5}^{+}$ & + & $\mathrm{NO}_{2}^{+}$ & & - & {$[77,46]$} \\
\hline & & $\mathrm{C}_{6} \mathrm{H}_{4}^{+}$ & + & $\mathrm{NO}_{2}^{+}$ & + & $1 \mathrm{H}$ & {$[76,46,1]$} \\
\hline & & $\mathrm{C}_{6} \mathrm{H}_{3}^{+}$ & + & $\mathrm{NO}_{2}^{+}$ & + & $2 \mathrm{H}$ & {$[75,46,2]$} \\
\hline & & $\mathrm{C}_{6} \mathrm{H}_{2}^{+}$ & + & $\mathrm{NO}_{2}^{+}$ & + & $3 \mathrm{H}$ & {$[74,46,3]$} \\
\hline & & $\mathrm{C}_{6} \mathrm{H}^{+}$ & + & $\mathrm{NO}_{2}^{+}$ & + & $4 \mathrm{H}$ & {$[73,46,4]$} \\
\hline & & $\mathrm{C}_{6}^{+}$ & + & $\mathrm{NO}_{2}^{+}$ & + & $5 \mathrm{H}$ & {$[72,46,5]$} \\
\hline & $\rightarrow$ & $\mathrm{C}_{5} \mathrm{H}_{5}^{+}$ & + & $\mathrm{NO}_{2}^{+}$ & + & $1 \mathrm{C}$ & {$[65,46,12]$} \\
\hline & & $\mathrm{C}_{5} \mathrm{H}_{4}^{+}$ & + & $\mathrm{NO}_{2}^{+}$ & + & $1 \mathrm{C} 1 \mathrm{H}$ & {$[64,46,13]$} \\
\hline & & $\mathrm{C}_{5} \mathrm{H}_{3}^{+}$ & + & $\mathrm{NO}_{2}^{+}$ & + & $1 \mathrm{C} 2 \mathrm{H}$ & {$[63,46,14]$} \\
\hline & & $\mathrm{C}_{5} \mathrm{H}_{2}^{+}$ & + & $\mathrm{NO}_{2}^{+}$ & + & $1 \mathrm{C} 3 \mathrm{H}$ & {$[62,46,15]$} \\
\hline & & $\mathrm{C}_{5} \mathrm{H}^{+}$ & + & $\mathrm{NO}_{2}^{+}$ & + & $1 \mathrm{C} 4 \mathrm{H}$ & {$[61,46,16]$} \\
\hline & & $\mathrm{C}_{5}^{+}$ & + & $\mathrm{NO}_{2}^{+}$ & + & $1 \mathrm{C} 5 \mathrm{H}$ & {$[60,46,17]$} \\
\hline & $\rightarrow$ & $\mathrm{C}_{4} \mathrm{H}_{3}^{+}$ & + & $\mathrm{NO}_{2}^{+}$ & + & $2 \mathrm{C} 2 \mathrm{H}$ & {$[51,46,26]$} \\
\hline & & $\mathrm{C}_{4} \mathrm{H}_{2}^{+}$ & + & $\mathrm{NO}_{2}^{+}$ & + & $2 \mathrm{C} 3 \mathrm{H}$ & {$[50,46,27]$} \\
\hline & & $\mathrm{C}_{4} \mathrm{H}^{+}$ & + & $\mathrm{NO}_{2}^{+}$ & + & $2 \mathrm{C} 4 \mathrm{H}$ & {$[49,46,28]$} \\
\hline & & $\mathrm{C}_{4}^{+}$ & + & $\mathrm{NO}_{2}^{+}$ & + & $2 \mathrm{C} 5 \mathrm{H}$ & {$[48,46,29]$} \\
\hline & $\rightarrow$ & $\mathrm{C}_{3} \mathrm{H}_{3}^{+}$ & + & $\mathrm{NO}_{2}^{+}$ & + & $3 \mathrm{C} 2 \mathrm{H}$ & {$[39,46,38]$} \\
\hline & & $\mathrm{C}_{3} \mathrm{H}_{2}^{+}$ & + & $\mathrm{NO}_{2}^{+}$ & + & $3 \mathrm{C} 3 \mathrm{H}$ & {$[38,46,39]$} \\
\hline & & $\mathrm{C}_{3} \mathrm{H}^{+}$ & + & $\mathrm{NO}_{2}^{+}$ & + & $3 \mathrm{C} 4 \mathrm{H}$ & {$[37,46,40]$} \\
\hline & & $\mathrm{C}_{3}^{+}$ & + & $\mathrm{NO}_{2}^{+}$ & + & $3 \mathrm{C} 5 \mathrm{H}$ & {$[36,46,41]$} \\
\hline & $\rightarrow$ & $\mathrm{C}_{2} \mathrm{H}_{3}^{+}$ & + & $\mathrm{NO}_{2}^{+}$ & + & $4 \mathrm{C} 2 \mathrm{H}$ & {$[27,46,50]$} \\
\hline & & $\mathrm{C}_{2} \mathrm{H}_{2}^{+}$ & + & $\mathrm{NO}_{2}^{+}$ & + & $4 \mathrm{C} 3 \mathrm{H}$ & {$[26,46,51]$} \\
\hline & & $\mathrm{C}_{2} \mathrm{H}^{+}$ & + & $\mathrm{NO}_{2}^{+}$ & + & $4 \mathrm{C} 4 \mathrm{H}$ & {$[25,46,52]$} \\
\hline & & $\mathrm{C}_{2}^{+}$ & + & $\mathrm{NO}_{2}^{+}$ & + & $4 \mathrm{C} 5 \mathrm{H}$ & {$[24,46,53]$} \\
\hline & $\rightarrow$ & $\mathrm{CH}_{4}^{+}$ & + & $\mathrm{NO}_{2}^{+}$ & + & $5 \mathrm{C} 1 \mathrm{H}$ & {$[16,46,61]$} \\
\hline & & $\mathrm{CH}_{3}^{+}$ & + & $\mathrm{NO}_{2}^{+}$ & + & $5 \mathrm{C} 2 \mathrm{H}$ & {$[15,46,62]$} \\
\hline & & $\mathrm{CH}_{2}^{+}$ & + & $\mathrm{NO}_{2}^{+}$ & + & $5 \mathrm{C} 3 \mathrm{H}$ & {$[14,46,63]$} \\
\hline & & $\mathrm{CH}^{+}$ & + & $\mathrm{NO}_{2}^{+}$ & + & $5 \mathrm{C} 4 \mathrm{H}$ & {$[13,46,64]$} \\
\hline & & $\mathrm{C}^{+}$ & + & $\mathrm{NO}_{2}^{+}$ & + & $5 \mathrm{C} 5 \mathrm{H}$ & {$[12,46,65]$} \\
\hline
\end{tabular}

formation of higher mass species 76 through $81 \mathrm{~m} / \mathrm{z}$, of which the former three are not present (Figure 4d). Upon first inspection, it therefore seems plausible to suggest that the $\mathrm{CE}$ of $\mathrm{NB}$ results in the formation of $\mathrm{NO}_{2}^{+}$and $\mathrm{C}_{5} \mathrm{H}_{\mathrm{n}}^{+}$ and $\mathrm{C}_{6} \mathrm{H}_{\mathrm{n}}^{+}$ions.

However, simplifying the CE process in this manner may not accurately describe the process. Conversion of the time-of-flight mass spectra into the momentum scaled spectrum along the direction parallel to the time-of-flight axis suggests that a variety of CE channels could be active. Conversion to the momentum scaled mass spectrum allows for identification of intermediate fragment ions from multiply charged Coulomb exploded molecular ions, as the fragments ions attain the same release momentum upon explosion. Chen et al. [10] demonstrate the utility of this conversion for the laser-induced dissociative ionization and Coulomb explosion of ethanol. The transformation from TOF mass spectrum into the momentum scaled spectrum along the parallel axis of the spectrometer is accomplished using the following equation

$$
P_{\|}=\frac{q\left(U_{1}-U_{2}\right)\left(t-t_{0}\right)}{d}
$$

where $q, U_{1}, U_{2}$, and $d$ have the same meaning as when defined for eq. 5 , and $t_{0}$ is the flight time for the central peak corresponding to zero momentum.
The NB mass spectrum of Figure 1c, taken at 795 nm, and converted into momentum scaled coordinates for selected ion species is shown in Figure 5. The utility of the momentum scaled coordinate is easily recognized for small molecules where the number of $\mathrm{CE}$ channels is limited to a few [10]. It the case of NB, the interpretation of the momentum scaled coordinate spectra may, at best, serve to qualitatively suggest pathways. As can be seen in Figure 5, the high mass fragments at 61 and 74 $\mathrm{m} / \mathrm{z}$ show a CE component consistent with the separation with $\mathrm{H}^{+}$, as well as components of momenta consistent with the release involving $\mathrm{O}^{+}[16 \mathrm{~m} / \mathrm{z}]$ and $\mathrm{NO}^{+}[30 \mathrm{~m} / z]$ for $\mathrm{C}_{5} \mathrm{H}^{+}[61 \mathrm{~m} / z]$, and $\mathrm{O}^{+}[16 \mathrm{~m} / \mathrm{z}], \mathrm{NO}^{+}$ [30 m/z]. and $\mathrm{NO}_{2}^{+}[46 \mathrm{~m} / \mathrm{z}]$ for $\mathrm{C}_{6} \mathrm{H}_{2}^{+}$[74 $\left.\mathrm{m} / \mathrm{z}\right]$. Air backgrounds (not shown) taken under the same experimental conditions show peaks at $m / z=1$ and 16, presumably from the dissociative ionization of water, but these ion peaks do not indicate CE structure, which implies that the release momenta seen in Figure 5 originates from the NB explosion. It therefore seems that there are a number of possibilities for the formation of the $\mathrm{C}_{5} \mathrm{H}_{\mathrm{n}}^{+}$and $\mathrm{C}_{6} \mathrm{H}_{\mathrm{n}}^{+}$fragments from the $\mathrm{CE}$ of $\mathrm{NB}$, and that the mass spectra suggest that these could involve the separation from $\mathrm{H}^{+}, \mathrm{O}^{+}, \mathrm{NO}^{+}$, and $\mathrm{NO}_{2}^{+}$.

Table 3(b). Potential CE pathways involved in the formation of $\mathrm{NO}^{+}$

\begin{tabular}{|c|c|c|c|c|c|c|c|}
\hline Reactant & & $\operatorname{Ion}_{1}^{+}$ & & $\operatorname{lon}_{2}^{+}$ & & Neutral & {$\left[\mathrm{m}_{1}, \mathrm{~m}_{2}, \mathrm{~N}\right]$} \\
\hline \multirow{34}{*}{$\mathrm{C}_{6} \mathrm{H}_{5} \mathrm{NO}_{2}$} & $\rightarrow$ & $\mathrm{C}_{6} \mathrm{H}_{5} \mathrm{O}^{+}$ & + & $\mathrm{NO}^{+}$ & & - & {$[93,30]$} \\
\hline & & $\mathrm{C}_{6} \mathrm{H}_{4} \mathrm{O}^{+}$ & + & $\mathrm{NO}^{+}$ & + & $1 \mathrm{H}$ & {$[92,30,1]$} \\
\hline & & $\mathrm{C}_{6} \mathrm{H}_{3} \mathrm{O}^{+}$ & + & $\mathrm{NO}^{+}$ & + & $2 \mathrm{H}$ & {$[91,30,2]$} \\
\hline & & $\mathrm{C}_{6} \mathrm{H}_{2} \mathrm{O}^{+}$ & + & $\mathrm{NO}^{+}$ & + & $3 \mathrm{H}$ & {$[90,30,3]$} \\
\hline & & $\mathrm{C}_{6} \mathrm{HO}^{+}$ & + & $\mathrm{NO}^{+}$ & + & $4 \mathrm{H}$ & {$[89,30,4]$} \\
\hline & & $\mathrm{C}_{6} \mathrm{O}^{+}$ & + & $\mathrm{NO}^{+}$ & + & $5 \mathrm{H}$ & {$[99,30,5]$} \\
\hline & $\rightarrow$ & $\mathrm{C}_{5} \mathrm{H}_{5} \mathrm{O}^{+}$ & + & $\mathrm{NO}^{+}$ & + & $1 \mathrm{C}$ & {$[81,30,12]$} \\
\hline & & $\mathrm{C}_{5} \mathrm{H}_{4} \mathrm{O}^{+}$ & + & $\mathrm{NO}^{+}$ & + & $1 \mathrm{C} 1 \mathrm{H}$ & {$[80,30,13]$} \\
\hline & & $\mathrm{C}_{5} \mathrm{H}_{3} \mathrm{O}^{+}$ & + & $\mathrm{NO}^{+}$ & + & $1 \mathrm{C} 2 \mathrm{H}$ & {$[79,30,14]$} \\
\hline & & $\mathrm{C}_{5} \mathrm{H}_{2} \mathrm{O}^{+}$ & + & $\mathrm{NO}^{+}$ & + & $1 \mathrm{C} 3 \mathrm{H}$ & {$[78,30,15]$} \\
\hline & & $\mathrm{C}_{5} \mathrm{HO}^{+}$ & + & $\mathrm{NO}^{+}$ & + & $1 \mathrm{C} 4 \mathrm{H}$ & {$[77,30,16]$} \\
\hline & & $\mathrm{C}_{5} \mathrm{O}^{+}$ & + & $\mathrm{NO}^{+}$ & + & $1 \mathrm{C} 5 \mathrm{H}$ & {$[76,30,17]$} \\
\hline & $\rightarrow$ & $\mathrm{C}_{4} \mathrm{H}_{5} \mathrm{O}^{+}$ & + & $\mathrm{NO}^{+}$ & + & $2 \mathrm{C}$ & {$[69,30,24]$} \\
\hline & & $\mathrm{C}_{4} \mathrm{H}_{4} \mathrm{O}^{+}$ & + & $\mathrm{NO}^{+}$ & + & $2 \mathrm{C} 1 \mathrm{H}$ & {$[68,30,25]$} \\
\hline & & $\mathrm{C}_{4} \mathrm{H}_{3} \mathrm{O}^{+}$ & + & $\mathrm{NO}^{+}$ & + & $2 \mathrm{C} 2 \mathrm{H}$ & {$[67,30,26]$} \\
\hline & & $\mathrm{C}_{4} \mathrm{H}_{2} \mathrm{O}^{+}$ & + & $\mathrm{NO}^{+}$ & + & $2 \mathrm{C} 3 \mathrm{H}$ & {$[66,30,27]$} \\
\hline & & $\mathrm{C}_{4} \mathrm{HO}^{+}$ & + & $\mathrm{NO}^{+}$ & + & $2 \mathrm{C} 4 \mathrm{H}$ & {$[65,30,28]$} \\
\hline & & $\mathrm{C}_{4} \mathrm{O}^{+}$ & + & $\mathrm{NO}^{+}$ & + & $2 \mathrm{C} 5 \mathrm{H}$ & {$[64,30,29]$} \\
\hline & $\rightarrow$ & $\mathrm{C}_{3} \mathrm{H}_{5} \mathrm{O}^{+}$ & + & $\mathrm{NO}^{+}$ & + & $3 C$ & {$[57,30,36]$} \\
\hline & & $\mathrm{C}_{3} \mathrm{H}_{4} \mathrm{O}^{+}$ & + & $\mathrm{NO}^{+}$ & + & $3 \mathrm{C} 1 \mathrm{H}$ & {$[56,30,37]$} \\
\hline & & $\mathrm{C}_{3} \mathrm{H}_{3} \mathrm{O}^{+}$ & + & $\mathrm{NO}^{+}$ & + & $3 \mathrm{C} 2 \mathrm{H}$ & {$[55,30,38]$} \\
\hline & & $\mathrm{C}_{3} \mathrm{H}_{2} \mathrm{O}^{+}$ & + & $\mathrm{NO}^{+}$ & + & $3 \mathrm{C} 3 \mathrm{H}$ & {$[54,30,39]$} \\
\hline & & $\mathrm{C}_{3} \mathrm{HO}^{+}$ & + & $\mathrm{NO}^{+}$ & + & $3 \mathrm{C} 4 \mathrm{H}$ & {$[53,30,40]$} \\
\hline & & $\mathrm{C}_{3} \mathrm{O}^{+}$ & + & $\mathrm{NO}^{+}$ & + & $3 \mathrm{C} 5 \mathrm{H}$ & {$[52,30,41]$} \\
\hline & $\rightarrow$ & $\mathrm{C}_{2} \mathrm{H}_{5} \mathrm{O}^{+}$ & + & $\mathrm{NO}^{+}$ & + & $4 C$ & {$[45,30,48]$} \\
\hline & & $\mathrm{C}_{2} \mathrm{H}_{4} \mathrm{O}^{+}$ & + & $\mathrm{NO}^{+}$ & + & $4 \mathrm{C} 1 \mathrm{H}$ & {$[44,30,49]$} \\
\hline & & $\mathrm{C}_{2} \mathrm{H}_{3} \mathrm{O}^{+}$ & + & $\mathrm{NO}^{+}$ & + & $4 \mathrm{C} 2 \mathrm{H}$ & {$[43,30,50]$} \\
\hline & & $\mathrm{C}_{2} \mathrm{H}_{2} \mathrm{O}^{+}$ & + & $\mathrm{NO}^{+}$ & + & $4 \mathrm{C} 3 \mathrm{H}$ & {$[42,30,51]$} \\
\hline & & $\mathrm{C}_{2} \mathrm{HO}^{+}$ & + & $\mathrm{NO}^{+}$ & + & $4 \mathrm{C} 4 \mathrm{H}$ & {$[41,30,52]$} \\
\hline & & $\mathrm{C}_{2} \mathrm{O}^{+}$ & + & $\mathrm{NO}^{+}$ & + & $4 \mathrm{C} 5 \mathrm{H}$ & {$[40,30,53]$} \\
\hline & $\rightarrow$ & $\mathrm{CH}_{3} \mathrm{O}^{+}$ & + & $\mathrm{NO}^{+}$ & + & $5 \mathrm{C} 2 \mathrm{H}$ & {$[31,30,62]$} \\
\hline & & $\mathrm{CH}_{2} \mathrm{O}^{+}$ & + & $\mathrm{NO}^{+}$ & + & $5 \mathrm{C} 3 \mathrm{H}$ & {$[30,30,63]$} \\
\hline & & $\mathrm{CHO}^{+}$ & + & $\mathrm{NO}^{+}$ & + & $5 \mathrm{C} 4 \mathrm{H}$ & {$[29,30,64]$} \\
\hline & & $\mathrm{CO}^{+}$ & + & $\mathrm{NO}^{+}$ & + & $5 \mathrm{C} 5 \mathrm{H}$ & {$[28,30,65]$} \\
\hline
\end{tabular}




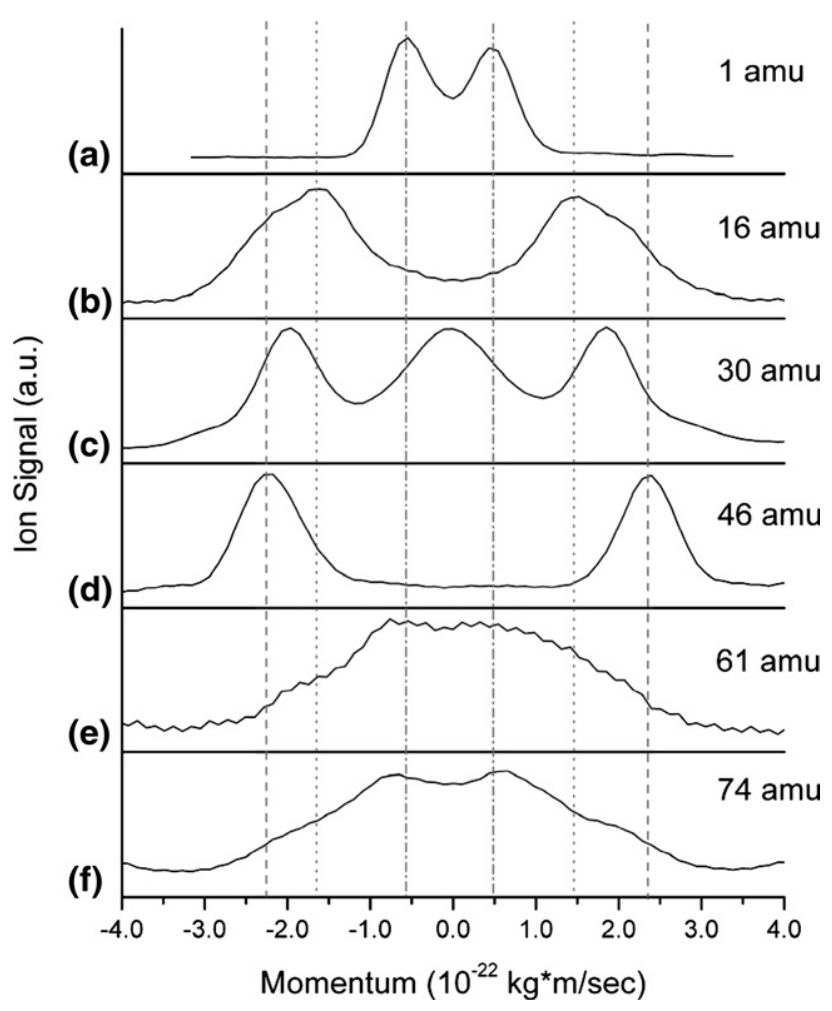

Figure 5. Momentum scaled mass spectra of fragment species resulting from the photoionization of $\mathrm{NB}$ at $795 \mathrm{~nm}$ and power density of $3.5 \times 10^{14} \mathrm{~W} / \mathrm{cm}^{2}$ : (a) $\mathrm{H}^{+}(1 \mathrm{~m} / \mathrm{z}),(\mathbf{b}) \mathrm{O}^{+}(16 \mathrm{~m} / \mathrm{z}),(\mathbf{c}) \mathrm{NO}^{+}$ $(30 \mathrm{~m} / \mathrm{z}),(\mathbf{d}) \mathrm{NO}_{2}^{+}(46 \mathrm{~m} / \mathrm{z}),(\mathbf{e}) \mathrm{C}_{5} \mathrm{H}^{+}(61 \mathrm{~m} / \mathrm{z})$, and $(\mathbf{f}) \mathrm{C}_{6} \mathrm{H}_{2}^{+}(74$ $\mathrm{m} / \mathrm{z}$ ). The vertical dashed lines are included to guide the eye down the figure.

Cooper et al. [41], in their VUV synchrotron study of $\mathrm{NB}$, found a number of ions with AEs much higher than anticipated from a calculation of their thermochemical thresholds (see their Table 2). They attribute the discrepancy in the measured AEs compared with the calculated thermochemical thresholds to be the result of ions originating from a sequential decomposition, rather than directly from a parent molecular ion. It is interesting to note that all of these species $\left(\mathrm{C}_{6} \mathrm{H}_{2}^{+}, \mathrm{C}_{5} \mathrm{H}_{2}^{+}\right.$, $\mathrm{C}_{4} \mathrm{H}_{2}^{+}$, and $\mathrm{C}_{3} \mathrm{H}_{2}^{+}$, for example) are present in mass spectra of the current experiment. Some of these species $\left(\mathrm{C}_{6} \mathrm{H}_{2}^{+}\right.$, in particular) are also the species potentially arising from a $\mathrm{CE}$ process. Further, the sequential decomposition product channels of Cooper et al. [41], identified as being the most plausible, correspond to dissociation into a number of neutral fragments, which include $\mathrm{NO}_{2}, \mathrm{NO}, \mathrm{O}, \mathrm{H}_{2}$, and $\mathrm{H}$. These are the same species identified in the momentum scaled mass spectra of this study as being consistent with origins from a CE pathway. Tasker et al. [28] suggested that the structure of the $\mathrm{NB}^{+}$ion is preserved in the $\mathrm{NB}^{2+}$ species, and further that the $\mathrm{CE}$ channels active in $\mathrm{NB}^{2+}$ should be similar to $\mathrm{NB}^{+}$. They further argue that $\mathrm{NO}_{2}^{+}$production is attributable to charge separation of the doubly charged molecular ion. These experiments corroborate the findings of Tasker et al. [28], and further indicate that at the power density employed in these experi- ments, $\mathrm{CE}$ is a complex process in which the product charges can reside on any number of fragments. In addition, these channels should result in the explosion of a number of neutral fragments, and while there is not likely time for sequential ionizations, the CE most probably results in similar decomposition pathways as suggested by Cooper et al. [41] Finally, the mass spectra indicate that MPI, high-energy ionizations/decompositions, and CE are all plausible channels in the photoionization of NB using $795 \mathrm{~nm}, 130 \mathrm{fs}, 3.5 \times 10^{14} \mathrm{~W} / \mathrm{cm}^{2}$ pulses.

An examination of the mass spectra of the rest of the series, DNB, MNT, DNT, and TNT reveal that similar processes are active in these molecules, although they are easiest to distinguish in MNT. MNT shows peaks at high $\mathrm{m} / \mathrm{z}$ with split structure at $73,74,75$, and 76 , and 85 , 86,87 , and 88 , for which there are a number of possibilities. These could include, but are not limited to, $\mathrm{C}_{5} \mathrm{H}_{\mathrm{n}}^{+}, \mathrm{C}_{2} \mathrm{H}_{\mathrm{n}} \mathrm{NO}_{2}^{+}, \mathrm{C}_{6} \mathrm{H}_{\mathrm{n}}^{+}, \mathrm{C}_{4} \mathrm{H}_{\mathrm{n}} \mathrm{O}^{+}, \mathrm{C}_{4} \mathrm{H}_{\mathrm{n}} \mathrm{NO}^{+}$, and $\mathrm{C}_{3} \mathrm{H}_{\mathrm{n}} \mathrm{NO}_{2}^{+}$. For the $\mathrm{C}_{5} \mathrm{H}_{\mathrm{n}}^{+}$and $\mathrm{C}_{6} \mathrm{H}_{\mathrm{n}}^{+}$, this implies that the $\mathrm{CE}$ channels could be similar to $\mathrm{NB}$, but shifted one carbon atom higher in mass due to the additional methyl group in toluene. While a number of studies have focused on the dissociation of the nitrotoluene isomers and the heats of formation of the intermediates, they have primarily focused on the main dissociation channels that involve $\mathrm{NO}_{2}, \mathrm{NO}$, and $\mathrm{OH}$ loss from the molecular ion, as well as $\mathrm{CO}$ loss from $\mathrm{C}_{7} \mathrm{H}_{6} \mathrm{NO}^{+}$. Tasker et al. [28] also investigated the MNT isomer at $3.8 \times 10^{15} \mathrm{~W} / \mathrm{cm}^{2}$ and $1.2 \times 10^{16} \mathrm{~W} / \mathrm{cm}^{2}$, and find in common with $\mathrm{NB}$, evidence of a $\mathrm{CE}$ mechanism which could occur through $\mathrm{NT}^{2+} \rightarrow \mathrm{C}_{7} \mathrm{H}_{7}^{+}+\mathrm{NO}_{2}^{+}$. They further postulate that it is probable that multiple electron ejection takes place within a doubly charged transient ion coming from one $\mathrm{C}-\mathrm{C}$ bond resulting in a ring opening process, making it impossible to exclude the acyclic (linear) ion [28]. The work of Tzallas et al. [17] provides further evidence that ring opening, induced by strong laser fields, is possible. It therefore seems reasonable to assume that the abovementioned channels are plausible candidates based on the split structure observed in the 70 and $80 \mathrm{~m} / \mathrm{z}$ range, and the indication in the momentum scaled mass spectrum of $\mathrm{NB}$ that the high mass fragments have release momenta consistent with $\mathrm{H}^{+}, \mathrm{O}^{+}, \mathrm{NO}^{+}$, and $\mathrm{NO}_{2}^{+}$.

A number of polarization dependent studies of molecular ionization in the tunnel regime indicate that the ion peak shape is dependent on the amount of geometric or dynamic alignment experienced by the molecule $[9,10,12,45-52]$. They generally find suppression of ionization when the polarization is circular, and enhancements of ionization in cases where the polarization is linear, with the CE component emphasized when the laser polarization is collinear with the time-of-flight spectrometer axis. In addition, ns-REMPI studies of $\mathrm{NO}_{2}$ and $\mathrm{NO}$, reported by Bornschlegl et al. [53], indicate that KER upon photoionization/dissociation, producing $\mathrm{NO}^{+}$and $\mathrm{O}\left({ }^{3} \mathrm{P}\right.$ or $\left.{ }^{1} \mathrm{D}\right)$, can lead to split TOF peak shapes, similar to those observed here for $\mathrm{NO}_{2}^{+}$ 
(a)

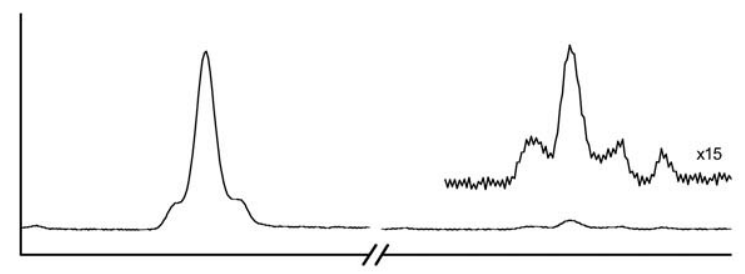

(b) 2

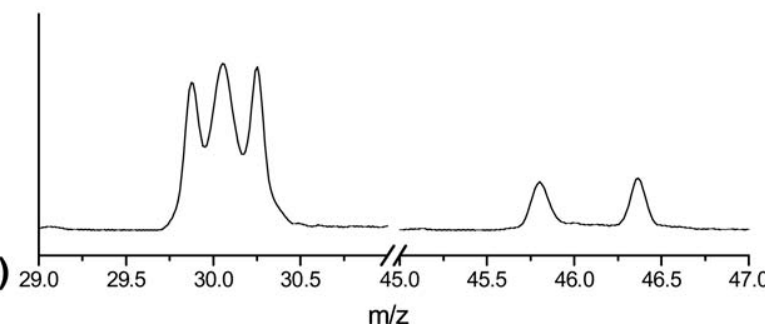

Figure 6. Peak shapes for the $\mathrm{NO}^{+}$and $\mathrm{NO}_{2}^{+}$species obtained from the photoionization of NB using $795 \mathrm{~nm}$ radiation with (a) vertical and (b) horizontal polarizations. When the laser polarization is horizontal, the axes of the time-of-flight extraction plane and laser polarization vector are parallel and the Coulomb explosion component of the time-of-flight peak shape is accentuated; (a) and (b) are plotted on the same scale so that the relative contribution at each polarization can be evaluated.

and $\mathrm{NO}^{+}$. It was therefore desirable to rotate the laser polarization from horizontal to vertical to verify that $\mathrm{CE}$ is indeed responsible for the splitting observed in these studies. Figure 6 shows the peak shapes for $\mathrm{NO}^{+}$and $\mathrm{NO}_{2}^{+}$obtained from NB photoionization using $795 \mathrm{~nm}$ radiation with vertical (6a) and horizontal (6b) polarizations. As can be seen from Figure 6, the outermost peak component, while reduced in magnitude, persists upon rotation of the laser polarization, further affirming the assumption that $\mathrm{CE}$ of the NB molecule is the process leading to the observed split peak shapes. Had it been KER associated with an ion and neutral fragment, we would anticipate only minor broadening of the central component of the singlet structure. It further suggests, as was already assumed, that the CE channel is unique to the nitro-aromatic species, since only singlet structure is observed when pure $\mathrm{NO}_{2}$ is photoionized under similar conditions (refer to Figure 3f).

\section{Conclusions}

The ultrafast-photoionization process of the explosives and ERCs have been investigated in a time-of-flight mass spectrometer at three wavelengths and power densities between $330 \mathrm{~nm}$ and $795 \mathrm{~nm}$ and $7.3 \times 10^{12}$ $\mathrm{W} / \mathrm{cm}^{2}$ to $3.5 \times 10^{14} \mathrm{~W} / \mathrm{cm}^{2}$ using $130 \mathrm{fs}$ laser pulses. These investigations reveal that the ultraviolet and visible wavelengths are much better at generating the parent molecular ion for each of the species investigated, in comparison to $795 \mathrm{~nm}$ radiation. In addition, at $795 \mathrm{~nm}$ and a power density of $3.5 \times 10^{14} \mathrm{~W} / \mathrm{cm}^{2}, \mathrm{CE}$ is thought to be a plausible mechanism for the formation of a number of fragment ion peaks observed in the mass spectra. This behavior is consistent with that expected by consideration of the adiabaticity parameter which predicts a shift from MPI to CE as the wavelength and power density is increased. Consideration of the NB mass spectrum suggests that the active $\mathrm{CE}$ channels result in the separation of transient species into at least two ionic fragments. Further, it seems plausible through an examination of the momentum scaled mass spectra that a number of the high mass fragments $\left(\mathrm{C}_{\mathrm{n}} \mathrm{H}_{\mathrm{n}}^{+}\right)$have a peak shape arising from its separation from $\mathrm{H}^{+}, \mathrm{O}^{+}, \mathrm{NO}^{+}$, or $\mathrm{NO}_{2}^{+}$, again consistent with a $\mathrm{CE}$ mechanism.

Moreover, our experimental results are consistent with the findings of Tasker et al. [28] and Cooper et al. [41]. Similarly, laser polarization studies suggest that the $\mathrm{CE}$ mechanism plays an important role in the photoionization of NB. We have shown this mechanism to be unique to nitro-aromatic compounds.

\section{Acknowledgments}

This material is based upon work supported by the National Science Foundation under grant CHE-0321288. The authors acknowledge the support by a sub-award agreement from The Johns Hopkins University with funds provided by grant no. DAAD 19-02-1-0255 from U.S. Army Robert Morris Acquisition.

\section{References}

1. L'Huilier, A.; Lompré, L. A.; Mainfray, G.; Manus, C. Multiply Charged Ions Induced by Multiphoton Absorption Processes in Rare-Gas Atoms at $1.064 \mu \mathrm{m}$. J. Phys. B: At. Mol. Opt. Phys. 1983, 16, 1363-1381.

2. Auguste, T.; Monot, P.; Lompré, L. A.; Mainfray, G.; Manus, C. Multiply Charged Ions Produced in Noble-Gases by a 1-ps Laser-Pulse at $\lambda=$ 1053 nm. J. Phys. B: At. Mol. Opt. Phys. 1992, 25, 4181-4194.

3. Fittinghoff, D. N.; Bolton, P. R.; Chang, B.; Kulander, K. C. Observation of Nonsequential Double Ionization of Helium with Optical Tunneling. Phys. Rev. Lett. 1992, 69, 2642-2645.

4. Walker, B.; Sheehy, B.; DiMauro, L. F.; Agostini, P.; Schafer, K. J.; Kulander, K. C. Precision Measurement of Strong Field Double Ionization of Helium. Phys. Rev. Lett. 1994, 73, 1227-1230.

5. Cornaggia, C.; Hering, P. Laser-Induced Non-Sequential Double Ionization of Small Molecules. J. Phys. B: At. Mol. Opt. Phys. 1998, 31, L503-L510.

6. Talebpour, A.; Larochelle, S.; Chin, S. L. Non-Sequential and Sequential Double Ionization of NO in an Intense Femtosecond Ti:Sapphire Laser Pulse. J. Phys. B: At. Mol. Opt. Phys. 1997, 30, L245-L250.

7. Sanderson, J. H.; Thomas, R. V.; Bryant, W. A.; Newell, W. R.; Taday, P. F.; Langley, A. J. Multielectron-Dissociative-Ionization of SF6 by Intense Femtosecond Laser Pulses. J. Phys. B: At. Mol. Opt. Phys. 1997, 30, 4499-4507.

8. Singhal, R. P.; Kilic, H. S.; Ledingham, K. W. D.; Kosmidis, C.; McCanny, T.; Langley, A. J.; Shaikh, W. Multiphoton Ionization and Dissociation of NO2 by 50 fs Laser Pulses. Chem. Phys. Lett. 1996, 253, 81-86.

9. Ren, H.; Wu, C.; Ma, R.; Yang, H.; Jiang, H.; Gong, Q. Field Ionization and Coulomb Explosion of Methanol in an Intense Field of a Femtosecond Laser Beam. Int. J. Mass Spectrom. 2002, 219, 305-313.

10. Chen, J.; Ma, R.; Ren, H.; Li, X.; Yang, H.; Gong, Q. Femtosecond Laser-Induced Dissociative Ionization and Coulomb Explosion of Ethanol. Int. J. Mass Spectrom. 2005, 241, 25-29.

11. Ma, R.; Ren, H.; Yang, H.; Jiang, H.; Gong, Q. Intense Femtosecond Laser Field-Induced Coulomb Fragmentation of C2H4. Int. J. Mass Spectrom. 2005, 242, 43-48.

12. Wu, C.; Ren, H.; Liu, T.; Ma, R.; Yang, H.; Jiang, H.; Gong, Q Laser-Induced Dissociation and Explosion of Methane and Methanol. J. Phys. B: At. Mol. Opt. Phys. 2002, 35, 2575-2582.

13. Harada, H.; Shimizu, S.; Yatsuhashi, T.; Sakabe, S.; Izawa, Y.; Nakashima, N. A Key Factor in Parent and Fragment Ion Formation on Irradiation with an Intense Femtosecond Laser Pulse. Chem. Phys. Lett. 2001, 342, 563-570

14. DeWitt, M. J.; Levis, R. J. Observing the Transition from a MultiphotonDominated to a Field-Mediated Ionization Process for Polyatomic Molecules in Intense Laser Fields. Phys. Rev. Lett. 1998, 81, 5101-5104.

15. Levis, R. J.; DeWitt, M. J. Photoexcitation, Ionization, and Dissociation of Molecules Using Intense Near-Infrared Radiation of Femtosecond Duration. J. Phys. Chem. A. 1999, 103, 6493-6507 and references therein.

16. Ledingham, K. W. D.; Singhal, R. P.; Smith, D. J.; McCanny, T.; Graham, P.; Kilic, H. S.; Peng, W. X.; Wang, S. L.; Langley, A. J.; Taday, P. F.; 
Kosmidis, C. Behavior of Polyatomic Molecules in Intense Infrared Laser Beams. J. Phys. Chem. A. 1998, 102, 3002-3005.

17. Tzallas, P.; Kosmidis, C.; Ledingham, K. W. D.; Singhal, R. P.; McCanny, T.; Graham, P.; Hankin, S. M.; Taday, P. F.; Langley, A. J. On the Multielectron Dissociative Ionization of Some Cyclic Aromatic Molecules Induced by Strong Laser Fields. J. Phys. Chem. A. 2001, 105, 529-536.

18. Tzallas, P.; Kosmidis, C.; Graham, P.; Ledingham, K. W. D.; McCanny, T.; Hankin, S. M.; Singhal, R. P.; Taday, P. F.; Langley, A. J. Coulomb Explosion in Aromatic Molecules and their Deuterated Derivatives. Chem. Phys. Lett. 2000, 332, 236-242.

19. Smith, D. J.; Ledingham, K. W. D.; Singhal, R. P.; McCanny, T.; Graham, P.; Kilic, H. S.; Tzallas, P.; Kosmidis, C.; Langley, A. J.; Taday, P. F. The Onset of Coulomb Explosions in Polyatomic Molecules. Rapid Commun. Mass Spectrom. 1999, 13, 1366-1373.

20. Robson, L.; Ledingham, K. W. D.; Tasker, A. D.; McKenna, P.; McCanny, T.; Kosmidis, C.; Jaroszynski, D. A.; Jones, D. R.; Issac, R. C.; Jamieson, S. Ionization and Fragmentation of Polycyclic Aromatic Hydrocarbons by Femtosecond Laser Pulses at Wavelengths Resonant with Cation Transitions. Chem. Phys. Lett. 2002, 360, 382-389.

21. Ledingham, K. W. D.; Smith, D. J.; Singhal, R. P.; McCanny, T.; Graham, P.; Kilic, H. S.; Peng, W. X.; Langley, A. J.; Taday, P. F.; Kosmidis, C. Multiply Charged Ions from Aromatic Molecules Following Irradiation in Intense Laser Fields, J. Phys. Chem. A. 1999, 103, 2952-2963.

22. Smith, D. J.; Ledingham, K. W. D.; Singhal, R. P.; Kilic, H. S.; McCanny, T.; Langley, A. J.; Taday, P. F.; Kosmidis, C. Time-of-Flight Mass Spectrometry of Aromatic Molecules Subjected to High Intensity Laser Beams. Rapid Commun. Mass Spectrom. 1998, 12, 813-820.

23. Shimizu, S.; Kou, J.; Kawato, S.; Shimizu, K.; Sakabe, S.; Nakashima, N. Coulomb Explosion of Benzene Irradiated by an Intense Femtosecond Laser Pulse. Chem. Phys. Lett. 2000, 317, 609-614.

24. Ledingham, K. W. D.; Kilic, H. S.; Kosmidis, C.; Deas, R. M.; Marshall, A.; McCanny, T.; Singhal, R. P.; Langley, A. J.; Shaikh, W. A Comparison of Femtosecond and Nanosecond Multiphoton Ionization and Dissociation for Some Nitro-Molecules. Rapid Commun. Mass Spectrom. 1995, 9, 1522-1527.

25. Kosmidis, C.; Ledingham, K. W. D.; Kilic, H. S.; McCanny, T.; Singhal R. P.; Langley, A. J.; Shaikh, W. On the Fragmentation of Nitrobenzene and Nitrotoluenes Induced by a Femtosecond Laser at $375 \mathrm{~nm}$. J. Phys. Chem. A. 1997, 101, 2264-2270.

26. Kilic, H. S.; Ledingham, K. W. D.; Kosmidis, C.; McCanny, T.; Singhal, R. P.; Wang, S. L.; Smith, D. J.; Langley, A. J.; Shaikh, W. Multiphoton Ionization and Dissociation of Nitromethane Using Femtosecond Laser Pulses at 375 and $750 \mathrm{~nm}$. J. Phys. Chem. A. 1997, 101, 817-823.

27. Tönnies, K.; Schmid, R. P.; Weickhardt, C.; Reif, J.; Grotemeyer, J. Multiphoton Ionization of Nitrotoluenes by Means of Ultrashort Laser Pulses. Int. J. Mass Spectrom. 2001, 206, 245-250.

28. Tasker, A. D.; Robson, L.; Ledingham, K. W. D.; McCanny, T.; Hankin, S. M.; McKenna, P.; Kosmidis, C.; Jaroszynski, D. A.; Jones, D. R. A High Mass Resolution Study of the Interaction of Aromatic and NitroAromatic Molecules with Intense Laser Fields. J. Phys. Chem. A. 2002, 106, 4005-4013.

29. Weickhardt, C.; Tonnies, K. Short Pulse Laser Mass Spectrometry of Nitrotoluenes: Ionization and Fragmentation Behavior. Rapid Commun. Mass Spectrom. 2002, 16, 442-446.

30. Hankin, S. M.; Tasker, A. D.; Robson, L.; Ledingham, K. W. D.; Fang, X.; McKenna, P.; McCanny, T.; Singhal, R. P.; Kosmidis, C.: Tzallas, P. Jaroszynski, D. A.; Jones, R.; Issac, R. C.; Jamison, S. Femtosecond Laser Time-of-Flight Mass Spectrometry of Labile Molecular Analytes: LaserDesorbed Nitro-Aromatic Molecules. Rapid Commun. Mass Spectrom. 2002, 16, 111-116.

31. Cabalo, I.; Sausa, R. C. Trace Detection of Explosives with Low Vapor Emissions by Laser Surface Photofragmentation-Fragment Detection Spectroscopy with an Improved Ionization Probe. Appl. Optics. 2005, 44, 1084-1091.

32. Lemire, G. W.; Simeonsson, J. B.; Sausa, R. C. Monitoring of VaporPhase Nitro-Compounds Using 226-nm Radiation-Fragmentation with Subsequent NO Resonance-Enhanced Multiphoton Ionization Detection. Anal. Chem. 1993, 65, 529-533.

33. Shu, J.; Bar, I.; Rosenwaks, S. Dinitrobenzene Detection by Use of One-Color Laser Photolysis and Laser-Induced Fluorescence of Vibrationally Excited NO. Appl. Optics. 1999, 38, 4705-4710.
34. Marshall, A.; Clark, A.; Jennings, R.; Ledingham, K. W. D.; Sander, J.; Singhal, R. P. Laser-Induced Dissociation, Ionization, and Fragmentation Processes in Nitroaromatic Molecules. Int. J. Mass Spectrom. 1992 116, 143-156

35. Wu, D.; Singh, J. P.; Yueh, F. Y.; Monts, D. L. 2,4,6-Trinitrotoluene Detection by Laser-Photofragmentation-Laser-Induced Fluorescence. Appl. Optics. 1996, 35, 3998-4003.

36. Marshall, A.; Clark, A.; Ledingham, K. W. D.; Sander, J.; Singhal, R. P.; Kosmidis, C.; Deas, R. M. Detection and Identification of Explosives Compounds Using Laser Ionization Time-of-Flight Techniques. Rapid Commun. Mass Spectrom. 1994, 8, 521-526.

37. Pond, B. V. Mullen, C. Suarez, I. Kessler, I : Brigos, K : Young S. E. Coggiola, M. J.; Crosley, D. R.; Oser, H. Detection of Explosive-Related Compounds by Laser Photoionization Time-of-Flight Mass Spectrometry. Appl. Phys. B: Lasers Opt. 2007, 86, 735-742.

38. Mullen, C.; Irwin, A.; Pond, B. V.; Huestis, D. L.; Coggiola, M. J.; Oser $\mathrm{H}$. Detection of Explosives and Explosives-Related Compounds by Single Photon Laser Ionization Time-of-Flight Mass Spectrometry. Anal. Chem. 2006, 78, 3807-3814

39. Lias, S. G.; Bartmess, J. E.; Liebman, J. F.; Holmes, J. L.; Levin, R. D. Mallard, W. D. In NIST Chemistry WebBook, NIST Standard Reference Database Number 69; Linstrom, P. J., Mallard, W. G., Eds.; National Institute of Standards and Technology: Gaithersburg, MD, 2005; http:/ / webbook.nist.gov.

40. Nagakura, S.; Kojima, M.; Maruyama, Y. Electronic Spectra and Electronic Structures of Nitrobenzene and Nitromesitylene. J. Mol. Spectrosc. 1964, 13, 174-192.

41. Cooper, L.; Shpinkova, L. G.; Rennie, E. E.; Holland, D. M. P.; Shaw, D. A. Time-of-Flight Mass Spectrometry Study of the Fragmentation of Valence Shell Ionized Nitrobenzene. Int. J. Mass Spectrom. 2001, 207, 223-239.

42. Brown, P. Kinetic Studies in Mass Spectrometry: Competing $\left[\mathrm{M}-\mathrm{NO}_{2}\right]$ and $[\mathrm{M}-\mathrm{NO}]$ Reactions in Substituted Nitrobenzenes. Approximate Activation Energies from Ionization and Appearance Potentials. Org. Mass Spectrom. 1970, 4, 533-544.

43. Tonnies, K.; Schmid, R. P.; Weickhardt, C.; Reif, J.; Grotemeyer, J. Multiphoton Ionization of Nitrotoluenes by Means of Ultrashort Laser Pulses. Int. J. Mass Spectrom. 2001, 206, 245-250.

44. Purnell, J.; Snyder, E. M.; Wei, S.; Castleman, A. W. Ultrafast LaserInduced Coulomb Explosion of Clusters with High Charge States. Chem. Phys. Lett. 1994, 229, 333-339.

45. Rosca-Pruna, F.; Springate, E.; Offerhaus, H. L.; Krishnamurthy, M. Farid, N.; Nicode, C.; Vrakking, M. J. J. Spatial Alignment of Diatomic Molecules in Intense Laser Fields: I. Experimental Results. J. Phys. B: At. Mol. Opt. Phys. 2001, 34, 4919-4938.

46. Normand, D.; Lompré, L. A.; Cornaggia, C. Laser-Induced Molecular Alignment Probed by a Double-Pulse Experiment. J. Phys. B: At. Mol. Opt. Phys. 1992, 25, L497-L503.

47. Frasinski, L. J.; Codling, K.; Hatherly, P.; Barr, J.; Ross, I. N.; Toner, W. T. Femtosecond Dynamics of Multielectron Dissociative Ionization by Use of Picosecond Laser. Phys. Rev. Lett. 1987, 58, 2424-2427.

48. Boyer, K.; Luk, T. S.; Solem, J. C.; Rhodes, C. K. Kinetic-Energy Distributions of Ionic Fragments Produced by Subpicosecond Multiphoton Ionization of $\mathrm{N}_{2}$. Phys. Rev. A. 1989, 39, 1186-1192.

49. Cornaggia, C.; Lavancier, J.; Normand, D.; Morellec, J.; Liu, H. X. Intensity Dependence of the Multielectron Dissociative Ionization of $\mathrm{N}_{2}$ at 305 and $610 \mathrm{~nm}$. Phys. Rev. A. 1990, 42, 5464-5472.

50. Posthumus, J. H.; Plumridge, J.; Thomas, M. K.; Codling, K.; Frasinski, L. J.; Langley, A. J.; Taday, P. F. Dynamic and Geometric Laser-Induced Alignment of Molecules in Intense Laser Fields. J. Phys. B: At. Mol. Opt. Phys. 1998, 31, L553-L562.

51. Shimizu, S.; Zhakhovskii, V. Sato, F; Okihara, S - Sakabe, S.; Nishihara K.; Izawa, Y.; Yatsuhashi, T.; Nakashima, N. Coulomb Explosion of Benzene Induced by an Intense Laser Field. J. Chem. Phys. 2002, 117, 3180-3189.

52. Poth, L.; Zhong, Q.; Ford, J. V.; Hurley, S. M.; Castleman, A. W. Charge Stripping Effects From Highly Charged Iodine Ions Formed from Coulomb Explosion of $\mathrm{CH}_{3}$ I Clusters. Chem. Phys. 1998, 239, 309-315.

53. Bornschlegl, A.; Weishaeupl, R.; Boesl, U. A New Approach for Fast, Simultaneous $\mathrm{NO} / \mathrm{NO}_{2}$ Analysis: Application of Basic Features of Multiphoton-Induced Ionization and Dissociation of $\mathrm{NO}_{\mathrm{x}}$. Anal. Bioanal. Chem. 2006, 384, 161-168. 